\title{
Axonal Conduction Delays, Brain State, and Corticogeniculate Communication
}

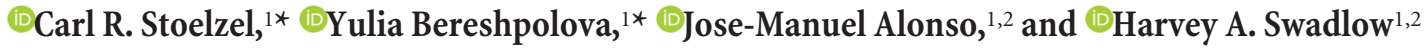 \\ ${ }^{1}$ Department of Psychology, University of Connecticut, Storrs, Connecticut 06269, and ${ }^{2}$ Department of Biological Sciences, State University of New York \\ College of Optometry, New York, New York 10036
}

Thalamocortical conduction times are short, but layer 6 corticothalamic axons display an enormous range of conduction times, some exceeding 40-50 ms. Here, we investigate (1) how axonal conduction times of corticogeniculate (CG) neurons are related to the visual information conveyed to the thalamus, and (2) how alert versus nonalert awake brain states affect visual processing across the spectrum of CG conduction times. In awake female Dutch-Belted rabbits, we found 58\% of CG neurons to be visually responsive, and $42 \%$ to be unresponsive. All responsive CG neurons had simple, orientation-selective receptive fields, and generated sustained responses to stationary stimuli. CG axonal conduction times were strongly related to modulated firing rates (F1 values) generated by drifting grating stimuli, and their associated interspike interval distributions, suggesting a continuum of visual responsiveness spanning the spectrum of axonal conduction times. CG conduction times were also significantly related to visual response latency, contrast sensitivity (C-50 values), directional selectivity, and optimal stimulus velocity. Increasing alertness did not cause visually unresponsive CG neurons to become responsive and did not change the response linearity (F1/F0 ratios) of visually responsive CG neurons. However, for visually responsive CG neurons, increased alertness nearly doubled the modulated response amplitude to optimal visual stimulation (F1 values), significantly shortened response latency, and dramatically increased response reliability. These effects of alertness were uniform across the broad spectrum of CG axonal conduction times.

Key words: alert brain state; corticothalamic; lateral geniculate nucleus; layer 6; neocortical axons; visual cortex

\section{Significance Statement}

Corticothalamic neurons of layer 6 send a dense feedback projection to thalamic nuclei that provide input to sensory neocortex. While sensory information reaches the cortex after brief thalamocortical axonal delays, corticothalamic axons can exhibit conduction delays of $<2 \mathrm{~ms}$ to $40-50 \mathrm{~ms}$. Here, in the corticogeniculate visual system of awake rabbits, we investigate the functional significance of this axonal diversity, and the effects of shifting alert/nonalert brain states on corticogeniculate processing. We show that axonal conduction times are strongly related to multiple visual response properties, suggesting a continuum of visual responsiveness spanning the spectrum of corticogeniculate axonal conduction times. We also show that transitions between awake brain states powerfully affect corticogeniculate processing, in some ways more strongly than in layer 4.

\section{Introduction}

Neurons of the LGN send a dense projection to layer 4 (L4), and a significant, but lesser projection to layer 6 (L6) of primary visual cortex (V1). In return, a subset of L6 neurons provides descend-

Received Feb. 16, 2017; revised May 18, 2017; accepted May 24, 2017.

Author contributions: C.R.S., Y.B., J.-M.A., and H.A.S. designed research; C.R.S., Y.B., and H.A.S. performed research; C.R.S., Y.B., J.-M.A., and H.A.S. analyzed data; C.R.S., Y.B., J.-M.A., and H.A.S. wrote the paper.

This work was supported by National Institutes of Health Grants EY024946 and EY018251. We thank Victor Serdyukov for expert software development and hardware support.

The authors declare no competing financial interests.

${ }^{*}$ C.R.S. and Y.B. contributed equally to this work.

Correspondence should be addressed to Dr. Harvey A. Swadlow, Department of Psychology (U-1020), University

of Connecticut, 406 Babbidge Road, U-1020, Storrs, CT 06269. E-mail: harvey.swadlow@uconn.edu.

DOI:10.1523/JNEUROSCI.0444-17.2017

Copyright $\odot 2017$ the authors $\quad 0270-6474 / 17 / 376342-17 \$ 15.00 / 0$ ing feedback to the LGN, providing excitatory glutamatergic synapses directly onto thalamic relay neurons, and disynaptic inhibition via the thalamic reticular nucleus (Alitto and Usrey, 2003). Notably, whereas the feedforward geniculocortical axonal conduction times are consistently very short, generally from $<1$ to a few milliseconds (Alonso et al., 2001; Briggs and Usrey, 2005; Stoelzel et al., 2008; Cleland et al., 1971; Swadlow and Weyand, 1985), conduction times along feedback CG axons cover an exceedingly broad spectrum, from very short ( $<2 \mathrm{~ms}$ ) to extremely long (up to 40-50 ms) (Tsumoto and Suda, 1980; Ferster and Lindstrom, 1983; Swadlow and Weyand, 1987; Briggs and Usrey, 2009). A similar diversity of L6 corticothalamic conduction times is seen in motor cortex of cats and rabbits (Beloozerova et al., 2003; Sirota et al., 2005), and in somatosensory cortex of rabbits (Swadlow, 
1989, 1990, 1991) and rats (Kwegyir-Afful and Simons, 2009). Here we examine, in awake rabbits, the functional significance of this extreme diversity in corticogeniculate conduction times.

We found $58 \%$ of CG neurons to be visually responsive, and $42 \%$ to be unresponsive, despite being tested in both alert and nonalert states. While the axonal conduction times of the unresponsive neurons were significantly longer than those of the visually responsive neurons, the distributions overlapped considerably. Visually responsive CG neurons had a seemingly homogeneous receptive field (RF) organization, showing simple, orientationselective RFs, a linear response to drifting grating stimuli (F1/F0 ratios $>1$ ), and a sustained response to stationary visual stimuli. However, the conduction times of CG axons were strongly related to the visual responsiveness (F1 and F0 values), to their associated interspike interval distributions, and to other response properties of the CG neuron (e.g., contrast, velocity, and directional tuning, visual response latency), despite the apparent homogeneity of the CG RFs.

We also examine the powerful effects of rapid and frequent shifts in waking brain state (e.g., Bereshpolova et al., 2011; Stoelzel et al., 2009; Harris and Thiele, 2011; Lee and Dan, 2012; Zhuang et al., 2014; McGinley et al., 2015) on CG visual processing. In simple cells of L4, although such shifts between alert and nonalert states have little or no effect on spontaneous firing or response linearity ( $\mathrm{F} 1 / \mathrm{F} 0$ ratios), they do have powerful effects on response gain (F1 values) and response reliability (Fano factor) (Zhuang et al., 2014), as they do in LGN neurons (Bezdudnaya et al., 2006; Cano et al., 2006). As we found in L4 simple cells, we found little effect of brain state on spontaneous firing rates or response linearity of CG neurons, and alertness did not cause visually unresponsive neurons to become responsive. However, alertness potently enhanced the amplitude of the visual responses of L6 CG neurons that were visually driven, shortened their visual response latencies, and dramatically increased their response reliability, and did so independently of CG axonal conduction times.

\section{Materials and Methods}

Recordings were obtained from monocular primary visual cortex (V1) of awake adult female Dutch-Belted rabbits. All experiments were conducted with the approval of the University of Connecticut Animal Care and Use Committee in accordance with National Institutes of Health guidelines.

Animal preparation and electrophysiological recording. The general surgical procedures for chronic recordings have been described recently (Zhuang et al., 2013, 2014) and are reported only briefly here. Under ketamine-acepromazine anesthesia, 8 stainless-steel screws and a stainless-steel rod, oriented in a rostrocaudal direction, were installed on the exposed surface of the skull by acrylic cement. The rod was then used to rigidly hold the rabbit during the electrode implantation and recording sessions. The space between the wound margin and the acrylic cement was filled with silicone rubber. Recordings were performed through a small hole in the skull after at least $10 \mathrm{~d}$ of recovery. Extracellular single-unit recordings were obtained from the monocular region of V1. Single-unit activity for most cells was studied using fine-diameter $(40 \mu \mathrm{m})$ quartz-insulated platinum/tungsten electrodes tapered and sharpened to a fine tip (impedance, 1.5-3 Mohm). A group of seven such electrodes was chronically implanted in a concentric array $(200 \mu \mathrm{m}$ separation), with tips initially located just above the dura. Each of these electrodes was independently controlled by a miniature microdrive (Swadlow et al., 2005). Multiunit activity from superficial layers of the superior colliculus was simultaneously recorded by a similar 3-channel microdrive system. Two stimulating electrodes (parylene-c insulated platinum/iridium microwire) were implanted in LGN for identification of cortical neurons. Neurons were antidromically identified using colli- sion and other methods, following electrical stimulation of the LGN (Swadlow and Weyand, 1987; Swadlow, 1989, 1998). Collision tests were used to antidromically identify nearly all (40 of 42 ) visually responsive CG neurons. However, due to a lack of spiking activity, only 11 of 33 nonvisually responsive CG neurons were identified using collision. The remaining neurons were considered to be antidromically activated if they satisfied each of two ancillary criteria in their responses to electrical stimulation of the LGN: (1) a refractory period of $\leq 2.0 \mathrm{~ms}$; and (2) an antidromic latency variability of either $<0.1 \mathrm{~ms}$ or $<1 \%$ of the antidromic latency (whichever is greater) to a test stimulus that followed a prior antidromic stimulus by 6-12 ms (Swadlow et al., 1978; Swadlow, 1989, 1998). All electrophysiological activity was acquired using a Plexon data acquisition system.

Brain state identification. During recordings, no anesthetic agents were applied, the eyes were open, and subjects were responsive to external stimuli (e.g., novel sound and gentle touch). Our goal was to record when subjects were awake, either alert or nonalert, in approximately equal proportions. In rabbits, wakefulness can be divided into alert and nonalert states. The alert state is indicated by hippocampal "theta" activity $(5-7 \mathrm{~Hz})$ and cortical desynchrony, and the nonalert state is indicated by hippocampal high-voltage irregular activity, and more slow-wave activity in the neocortex (Swadlow and Gusev, 2001; Bezdudnaya et al., 2006; Cano et al., 2006; Stoelzel et al., 2008, 2009; for discussion of nonalert state vs sleep states in rabbits, see Bereshpolova et al., 2011; Zhuang et al., 2013). The hippocampal EEG was segmented by visual inspection into alert versus nonalert states based on the presence of theta activity (5-7 $\mathrm{Hz}$ ) or high-voltage, irregular activity, respectively. This segmentation was aided and verified by fast Fourier transform analysis. Some nonperiodic sensory stimulation (random sounds, tactile stimulation, movements in room) is often required to keep rabbits from transitioning from the awake, nonalert state to sleep (early signs of which are indicated by cortical spindle activity), and such stimulation was applied when needed. In some cases, when rabbits became drowsy during extended recordings, we provided novel sounds to generate alertness. If they were difficult to arouse, we let them sleep for a while, and did not collect data during these periods. For analyses not involving state, we used all of the data, both alert and nonalert. For state analyses (see Figs. 9D, 1213-14), we segmented the data files into alert and nonalert components (as above) and used all of such state-segmented data for our analyses.

Identification of L6 CG neurons and estimates of axonal conduction velocity. For most microelectrode penetrations, full-field flash-evoked LFPs were recorded systematically as the electrode was lowered. We have shown that the reversal depth of short-latency flash-evoked field potentials (Fig. 1A) in rabbit V1 occurs in L2/L3, and that L4 lies $\sim 100$ to 500 $\mu \mathrm{m}$ below this reversal point (Stoelzel et al., 2008; Zhuang et al., 2014). We have also shown (1) that the great majority of retrogradely labeled corticotectal neurons in rabbit V1 are in L5 (a very few are in L4) (Swadlow and Weyand, 1981); and (2) that antidromically activated corticotectal neurons in rabbit V1 (48 of 48 studied) are found from 400 to 700 $\mu \mathrm{m}$ below the flash reversal point (Fig. 1B) (Bereshpolova et al., 2007). Because corticotectal neurons are rare in the deepest $100 \mu \mathrm{m}$ of L5 (Swadlow and Weyand, 1981) (see Figs. 2C, 6), we can infer from the above considerations that the border between L5 and L6 lies $\sim 800 \mu \mathrm{m}$ below the flash reversal point in rabbit V1. Neurons below this depth were considered to be in L6, and those that were antidromically activated via LGN stimulation were classified as CG neurons.

In addition to the above depth analysis, which was available for 27 of the 42 visually responsive CG neurons, and 18 of the 31 visually unresponsive CG neurons that we studied, we also identified what we defined as the "most superficial CG neuron" in each penetration. This "most superficial CG neuron" was required to show: (1) an antidromic latency to LGN stimulation of $>5 \mathrm{~ms}$, and (2) a "supernormal" decrease in antidromic latency (Gardner-Medwin, 1972; Swadlow and Waxman, 1975; Swadlow 1985, 1998) to the second of two electrical stimuli presented to the LGN at an interval of 6-12 ms. This testing was used because (1) it allowed us to identify CG neurons when the flash-evoked reversal depth was not known, and (2) it provided added evidence that neurons activated antidromically via LGN stimulation were, indeed, CG neurons, and not L5 corticotectal neurons activated in passage. These criteria were 
A

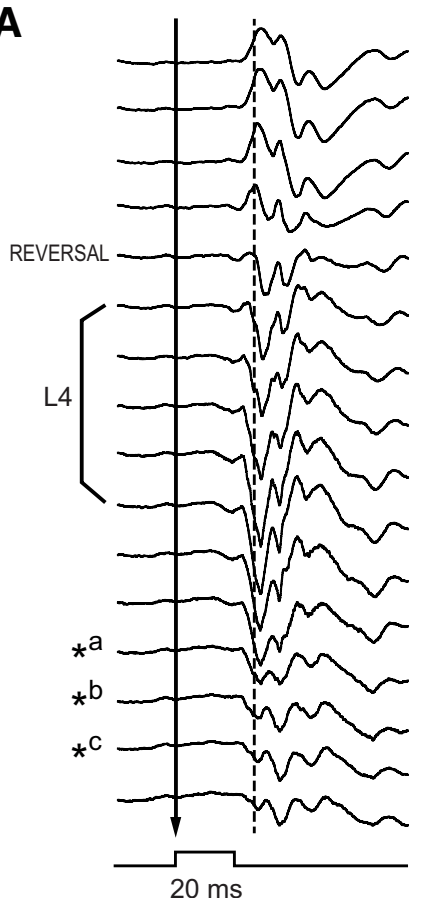

B

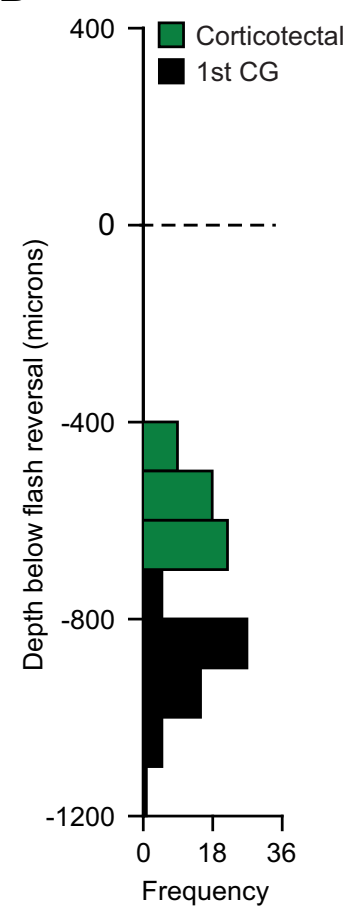

Figure 1. Depth distribution of antidromically identified CG neurons. $A$, An example of the flash-evoked field potentials recorded from V1 using a 16-channel silicone probe (vertical spacing, $100 \mu \mathrm{m}$ ). The reversal point for these field potentials is the fifth channel from the top. Brackets indicate the estimated position of $L 4$. In this penetration, antidromically identified CG neurons (see Materials and Methods) were recorded on channels 13-15 (800-1000 $\mu \mathrm{m}$ beneath the flash reversal point) with the following antidromic latencies: ${ }^{*} \mathrm{a}=20 \mathrm{~ms} .{ }^{*} \mathrm{~b}=3.5$ ms and $33 \mathrm{~ms} .{ }^{*} \mathrm{C}=23 \mathrm{~ms}$. $\boldsymbol{B}$, The frequency distribution of depths for the first antidromically identified $(G$ neurons (black bars) in each penetration with respect to the flash reversal point. The relative depth of antidromically identified corticotectal neurons (green bars, taken from Bereshpolova et al., 2007), obtained using the same methods, is provided for reference.

based on differences in the axonal characteristics of L6 versus L5 descending corticofugal axons studied in visual, somatosensory, and motor cortex of rabbits (below), as well as in somatosensory cortex of the rat (Beierlein and Connors, 2002; Kelly et al., 2001). Thus, in rabbits, (1) whereas the great majority of L 5 corticofugal neurons have fast-conducting axons, with antidromic latencies of $<3 \mathrm{~ms}$, L6 corticothalamic neurons are slowly conducting, (2) whereas the great majority of L5 corticotectal neurons show minimal or no supernormality (Swadlow, 1985, their Fig. 10; Swadlow, 1989), L6 corticofugal neurons show prominent "supernormal" axonal conduction following prior impulse activity (Swadlow and Weyand, 1987; Swadlow, 1989, 1990, 1991).

In summary, neurons antidromically activated via stimulation of the LGN were identified as bona fide CG neurons in one of two ways: either they were (1) $>800 \mu \mathrm{m}$ below the flashed-evoked reversal point, or (2) they were at the same depth, or deeper than the "most superficial CG neuron" in the penetration, as defined above. Notably, in 24 of 28 penetrations in which both tests were available, the most superficial CG neuron was found between 800 and $1000 \mu \mathrm{m}$ beneath the flash-evoked reversal point. In only 2 cases was it more superficial $(720 \mu \mathrm{m}$ beneath the reversal point, in both cases).

Estimations of CG axonal conduction velocity were based on estimates of conduction distance that were divided by the estimated conduction time. Thus, they represent an average conduction velocity along the length of axon between the stimulation site (near the terminals in the LGN) and the soma. Axonal conduction time was approximated by subtracting $0.2 \mathrm{~ms}$ from the antidromic latency (to compensate for utilization time at the stimulation site and delay of invasion near the soma). We estimated axonal conduction distance to be $17 \mathrm{~mm}$, based on previous measures in Dutch-Belted rabbits (Swadlow and Weyand, 1981). It is not

possible to rigorously extrapolate from conduction velocity to myelination/nonmyelination of the axon. Central axons may gain or lose myelin along their course, especially near their preterminal branches. It is possible, however, making conservative assumptions based on the known morphology and conduction properties of central unmyelinated and myelinated axons to draw some general guidelines for extrapolating from conduction velocity measures to questions of myelination. We have previously done this for callosal axons (Swadlow and Waxman, 1976; Waxman and Swadlow, 1976), where we concluded that axons with mean conduction velocities of $>3.4 \mathrm{~m} / \mathrm{s}$ were very likely to be myelinated along most of their length, whereas those of $<0.8 \mathrm{~m} / \mathrm{s}$ were very likely to be nonmyelinated along most of their length (Merrill et al., 1978; Swadlow, 1985; Meeks and Mennerick, 2007; see also Dellal et al., 2012). Although our main conclusions do not depend upon estimates of myelination/ nonmyelination, we offer them to put the conduction velocity measures into some perspective.

Visual stimulation and eye movement control. Visual stimulation protocols were similar to what have been published previously (Zhuang et al., 2013). All visual stimuli were presented by a CRT monitor (Nec MultiSync $40 \times 30 \mathrm{~cm}$, mean luminance $48 \mathrm{~cd} / \mathrm{m}^{2}$, refresh rate $160 \mathrm{~Hz}$ ). First, the cell's ON-OFF subfields were mapped with sparse noise stimulation by reverse correlation. Second, the cell's sustained/transient property was measured with flashing stationary stimuli, which were optimized to elicit the strongest response possible (see below for definition of sustained index). Third, circular drifting gratings were used to further measure the cell's response properties. The cell's tuning properties were measured by pseudorandomly varying one of four grating parameters (orientation, spatial frequency, temporal frequency, or contrast) while keeping the other three parameters at optimal values. Each presentation of a particular parameter combination lasted for 3-8 s with $2 \mathrm{~s}$ gaps in between, and all tested parameter combinations were presented for at least 100 periods. During testing of visual response properties, the RF center was constantly tracked by dynamic calculation of RF position from multiunit recordings in the superior colliculus. Movies of the eye were also obtained with a high frequency infrared video tracking system (Arrington Research), and the position of the pupil center was tracked. If an eye movement occurred during testing, the relation between the RF center of the cortical cell and the superior colliculus multiunit RF center was used to dynamically place the stimulus on the cortical RF. Data within \pm 15 s of eye movements was discarded in offline analysis (Zhuang et al., 2013).

Latency to flash stimulation. The latency to flash stimulation was measured from the cell's response to optimal flashing stimuli, as in Zhuang et al. (2013, 2014). The poststimulus histogram (PSTH; with bin size equal to $1 \mathrm{~ms}$ ) around the onset of the stimuli was generated and smoothed by applying a sliding boxcar filter with width of $30 \mathrm{~ms}$. Each stimulus frame was time-stamped, and the stimulus onset time was corrected for the position of the stimulus on the monitor screen (stimulus presentation onset is faster in the upper half than lower half of the monitor). Latency was defined as the time at which the smoothed function first passed $40 \%$ of its maximum value.

Offline data analysis. Spikes from cortical single units were isolated during the experiment and verified offline by using Plexon cluster analysis software. All data analysis was then performed with NeuroExplorer (Nex Technologies) and MATLAB (The MathWorks).

Statistics. Parametric tests were used when groups passed normality (using Shapiro-Wilk test). In the case of brain state (paired) comparison, normality was tested on the difference between alert and nonalert measures. When a dataset failed normality, comparisons were made using the Wilcoxon signed rank test for paired data and the Mann-Whitney $U$ test for unpaired data. In figures and text, data are presented as mean $\pm \mathrm{SE}$, with $p$ values. The Hartigan Dip Test was used to examine bimodality/ multimodality of distributions.

Spatiotemporal RFs. For each cell, the raw ON and OFF RF matrices were generated by reverse correlation within a $20 \mathrm{~ms}$ time window around the peak response (Jones and Palmer, 1987). A Gaussian filter was applied to smooth these matrices. Finally, the processed ON and OFF RF maps were generated by applying a threshold as $30 \%$ of maximum pixel value. From this map, the position of maximal response and the sign of 
the RF were determined. Cortical simple cells were identified by possessing an RF with one or more spatially separated ON and/or OFF subfields (as in Zhuang et al., 2013).

The temporal evolution of the RF map was measured by calculating a series of RF maps, each with a temporal window $20 \mathrm{~ms}$ wide, and a sliding window of $5 \mathrm{~ms}$ from 0 to $120 \mathrm{~ms}$ preceding each CG action potential. The RF center response was measured for each frame by summing the RF map in the $3 \times 3$ degree area centered on the position of the maximal response, and these measures were fitted with a Gaussian function.

Drifting grating parameter tuning properties. The mean firing rate (F0 component) and first harmonic component (F1) of the PSTH responding to drifting grating stimuli were calculated by Fourier analysis. The maximum F1 and maximum F0 responses were measured for each cell. Spatial summation linearity was calculated as the F1/F0 ratios measured from the PSTH with strongest F1 response. Reliability was measured with an optimized grating stimulus as the Fano factor (variance/mean) with a bin size equal to the period of the stimulation. All visually responsive CG neurons were simple cells (defined by segregated ON and OFF RF subregions), and all had stronger F1 than F0 responses (see Results). Therefore, the F1 response was used to measure tuning properties for CG neurons.

Contrast tuning responses were tested on eight different contrasts ranging from $1 \%$ to $95 \%$ (Cano et al., 2006). Because some visual cortical neurons show decreased responses at high contrast (high-contrast suppression) (Zhuang et al., 2013), F1 and F0 responses were fitted by a hyperbolic model with (Peirce, 2007) or without (Naka and Rushton, 1966; Albrecht and Hamilton, 1982) high-contrast suppression modification, as follows: F0 response without high-contrast suppression: $y=R_{0}+A \times$ $x^{n} /\left(C^{n}+x^{n}\right)$; F0 response with high-contrast suppression: $y=R_{0}+A \times$ $x^{n} /\left(C^{s n}+x^{s n}\right)$; F1 response without high-contrast suppression: $y=A \times x^{n} /$ $\left(C^{n}+x^{n}\right)$; F1 response with high-contrast suppression: $y=A \times x^{n} /\left(C^{s n}+\right.$ $\left.x^{s n}\right)$. Here $A$ is the response amplitude, $x$ is the contrast value, and $C$ is the contrast at which the cell's response first reaches the middle point of the range from baseline to maximum response. However, the parameters extracted from the fit do not faithfully represent the values of the contrast response function in the model with high-contrast suppression, which can span to contrast values $>100 \%$. Therefore, the response amplitude $\left(R_{\text {con }}\right)$ and the C-50 were calculated by limiting the fitting function within a contrast ranging from $0 \%$ to $100 \%$. All contrast response functions were fitted with and without high-contrast suppression, and the $R^{2}$ of fitness normalized by degree of freedom (df) was measured in both fits (Peirce, 2007): $R_{\text {nor }}^{2}=1-\left(1-R^{2}\right) / d f$. The model with higher $R_{\text {nor }}^{2}$ was chosen to extract the parameters $R_{\text {con }}$ and C-50.

Orientation tuning was measured with drifting gratings differing in orientation/direction by 15-30 degrees. Tuning curves were fitted by von Mises distribution functions (Nowak et al., 2008) as follows:

$$
\begin{aligned}
y=R_{0}+A_{1} \exp \left\{k\left[\cos \left(x-O R_{\text {peak }}\right)-1\right]\right\} \\
+A_{2} \exp \left\{k\left[\cos \left(x-O R_{\text {peak }}+\pi\right)-1\right]\right\}, \text { where } A_{1} \geq A_{2}
\end{aligned}
$$

Here the independent variable $x$ (the moving direction of the tested drifting grading) is presented in radians. From this model, $R_{0}$ represents the baseline of the curve, $A_{1}$ and $A_{2}$ represent the response amplitude to the preferred direction $\left(O R_{\text {peak }}\right)$ and to the opposite of preferred direction, respectively. $k$ is a width factor.

To measure the orientation selectivity and direction selectivity, the circular variance (CirVar) (Ringach et al., 2002), orientation selectivity index (OSI), and direction selectivity index (DSI) were calculated as follows:

$$
\text { CirVar }=1-\left|\frac{\sum R_{j} e^{i 2 \theta_{j}}}{\sum R_{j}}\right|
$$

where $j$ represents all the directions in the orientation tuning curve; $R_{j}$ and $\theta_{j}$ represent the cell response (spikes/s) and the angle (in radians) of $j$ th direction, respectively, as follows:

$$
\text { OSI }=\frac{\left(R_{\text {pref }}-R_{\text {orth }}\right)}{\left(R_{\text {pref }}+R_{\text {orth }}\right)}, \quad \text { where } R_{\text {orth }}=\frac{R_{\text {pref }+\frac{\pi}{2}+R_{\text {pref }-\frac{\pi}{2}}}}{2}
$$

$$
D S I=\frac{\left(R_{p r e f}-R_{o p p o}\right)}{\left(R_{p r e f}+R_{o p p o}\right)},
$$

where $R_{\text {pref }}$ represents the cell's response in the preferred direction, $R_{\text {orth }}$ represents the cell's mean responses of the two directions orthogonal to the preferred direction, and $R_{\text {oppo }}$ represents the cell's response to the opposite of the preferred direction. All three measurements (CirVar, OSI, and DSI) have values ranging from 0 to 1, with higher CirVar meaning weaker orientation selectivity, higher OSI meaning stronger orientation selectivity, and higher DSI meaning stronger direction selectivity.

Spatial frequency responses were tested from 0.00825 to $1.32 \mathrm{cpd}$ (for some cells from 0.05 to $1.32 \mathrm{cpd}$ ). The response tuning data were fitted by Gaussian model as follows:

$$
y=R_{0}+R_{S F} x \exp \left[-\left(x-S F_{p e a k}\right)^{2} / 2 \sigma_{S F}^{2}\right]
$$

From the model, the amplitude $\left(R_{S F}\right)$ and the spatial frequency with peak response $\left(S F_{\text {peak }}\right)$ were extracted. While tuning width for bandpass cells was measured as the range between two spatial frequencies with halfmaximal response on logarithmic scale $\left(S F_{\text {width }}\right)$ as follows:

$$
S F_{\text {width }}=\log _{10}\left[\left(S F_{\text {peak }}+1.1774 \times \sigma_{S F}\right) /\left(S F_{\text {peak }}-1.1774 \times \sigma_{S F}\right)\right]
$$

Temporal frequency responses were tested on six different temporal frequencies $(0.5,1,2,4,8$, and $16 \mathrm{~Hz})$. The temporal frequency tuning curve was fitted by Gaussian model on logarithmic scale (with base 2) (modified from Bezdudnaya et al., 2006) as follows:

$$
y=R_{0}+R_{T F} \times \exp \left\{-\left[\log _{2}(X)-\log _{2}\left(T F_{p e a k}\right)\right]^{2} / 2 \sigma_{T F}^{2}\right\}
$$

From the model, the amplitude $\left(R_{T F}\right)$ and the temporal frequency with peak response $\left(T F_{\text {peak }}\right)$ were extracted. Temporal frequency tuning width was measured as the width at half-height on logarithmic scale $\left(T F_{\text {width }}\right.$, with base 2), as follows: $T F_{\text {width }}=2.35482 \times \sigma_{T F}$.

Sustained/transient responses. We classified cortical neurons as responding in a sustained or transient manner to a flashing stationary stimulus, which was optimized to elicit the strongest response possible. This test was done when subjects were alert because sustained responses are strongly reduced when rabbits are nonalert (Swadlow and Weyand, 1985, 1987; Bezdudnaya et al., 2006; Zhuang et al., 2014). The stimulus was either a circle or rectangle optimized for size, orientation, and contrast polarity (dark or light). The stimulus was presented for $2 \mathrm{~s}$ on $2 \mathrm{~s}$ off. A "sustained index" (SI) was calculated as the ratio between the cell's maintained visual response and the baseline activity. The maintained visual response was measured as the mean firing rate from 0.5 to $1.0 \mathrm{~s}$ after the onset of the optimal stationary stimulus, and the baseline activity was measured as the mean firing rate during the $1 \mathrm{~s}$ period before the stimuli. Sustained cells were defined by having SIs of at least 2 and having a maintained visual response of $>1$ spike/s. Cells with SIs of $<2$ would be classified as transient, but all L6 CG neurons were found to be "sustained." Because many L6 CG neurons lack any spontaneous activity (see Fig. 2, which would result in infinitely high SIs), we assigned, a minimum baseline firing rate of 0.05 spikes/s to all CG neurons for this calculation. We also calculated a "transient/sustained ratio" for all CG neurons. To do this, we measured the peak value of the transient response (during the $15 \mathrm{~ms}$ period centered on the initial peak response) and divided it by the maintained visual response (as defined above).

\section{Results}

We identified 101 CG neurons, with antidromic latencies of 1.6-49 ms (mean: $24.0 \pm 11.94 \mathrm{~ms}$ ). These neurons consisted of three subgroups: (1) 42 CG cells were tested, and responsive to visual stimulation; (2) 31 CG cells were tested for visual stimulation but were unresponsive; and (3) 28 CG cells were tested only for their axonal properties, not visual properties. Given a conduction distance of $\sim 17 \mathrm{~mm}$ for rabbit monocular geniculocortical connectivity (Swadlow and Weyand, 1981), this range of antidromic conduction times correspond to axonal conduction velocities of $\sim 0.35-12 \mathrm{~m} / \mathrm{s}$. Figure $2 A 1$ shows the frequency dis- 
A 1

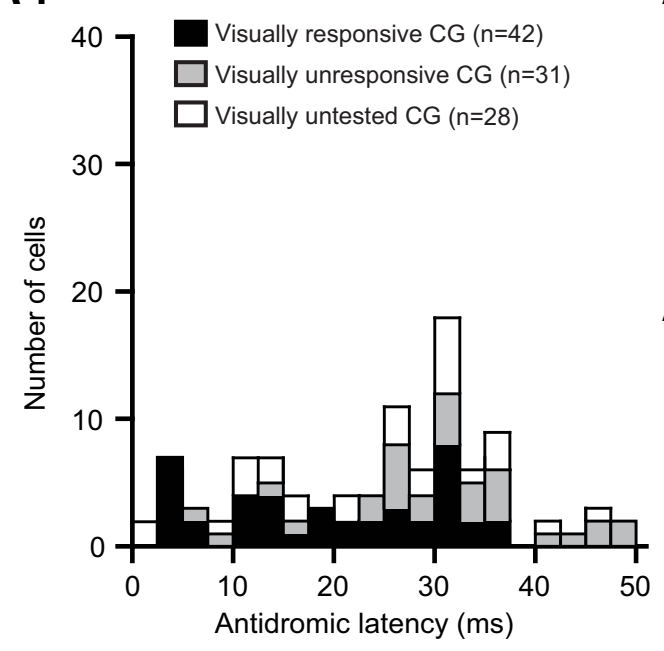

A2

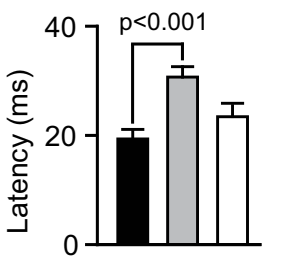

A3

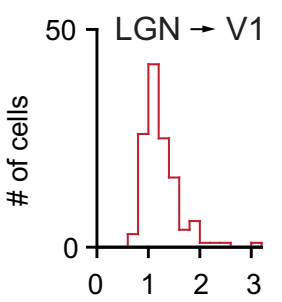

Antidromic latency $(\mathrm{ms})$
B

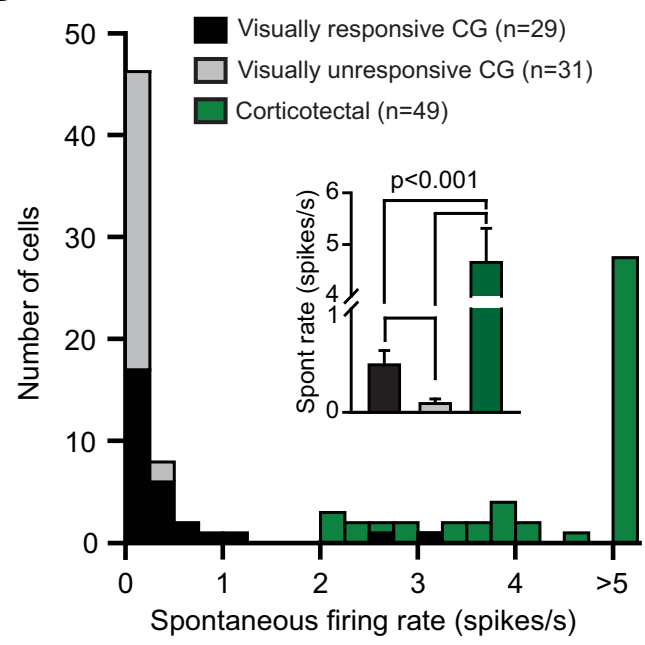

Figure 2. CG neurons exhibited a very wide range of axonal conduction times. A1, Frequency distribution of antidromic latencies for visually responsive (G neurons (black bars), $(G \mathrm{G}$ neurons that were unresponsive to visual stimulation (gray bars), and (G neurons that were not visually tested (white bars). A2, Means for these subgroups of (G cells. A3, For comparative purposes, frequency distribution of the antidromic latencies of LGN thalamocortical neurons in rabbit (from Swadlow and Weyand, 1985). B, Frequency distribution of spontaneous firing rates for visually responsive and unresponsive $G$ neurons and, for comparative purposes, for the corticotectal neurons shown in Figure $1 B$ (from Bereshpolova et al., 2007). Note the nearly nonoverlapping distributions of these populations. Inset, Mean \pm SEM for these groups of cells, along with the values for the $L 5$ corticotectal neurons.

\section{A}

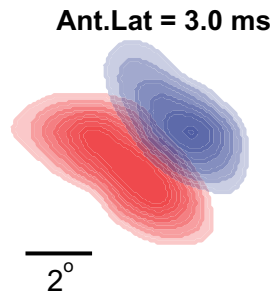

B
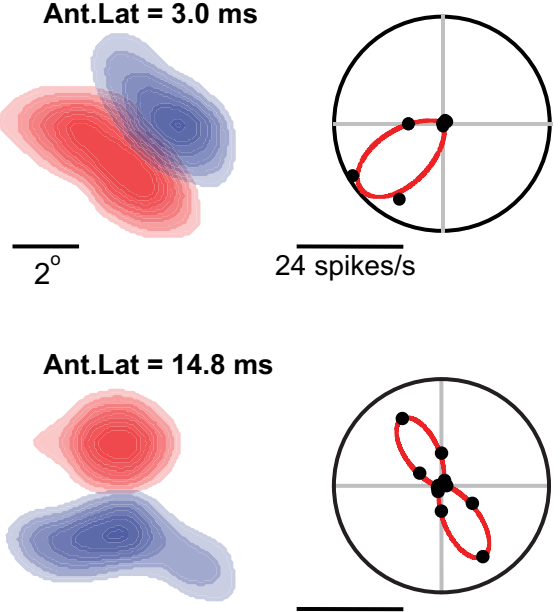

$2 \overline{4 \text { spikes } / \mathrm{s}}$

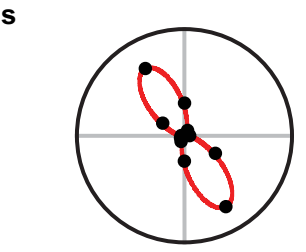

16 spikes/s
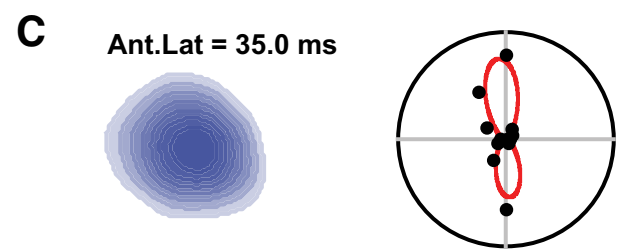

$4 \overline{\text { spikes/s }}$
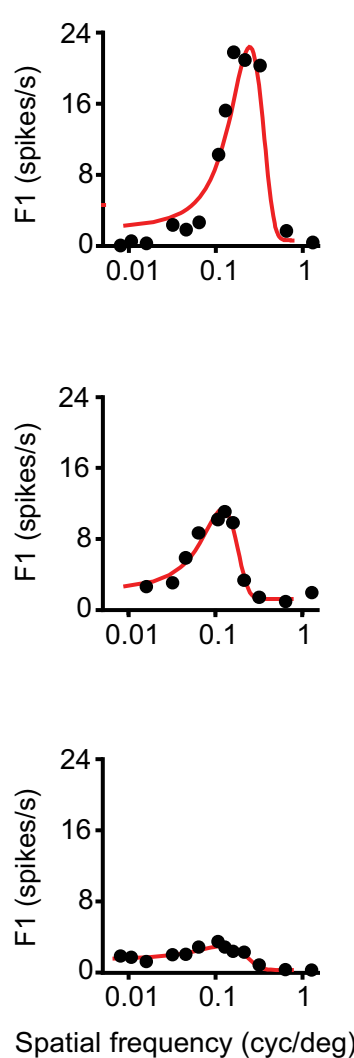
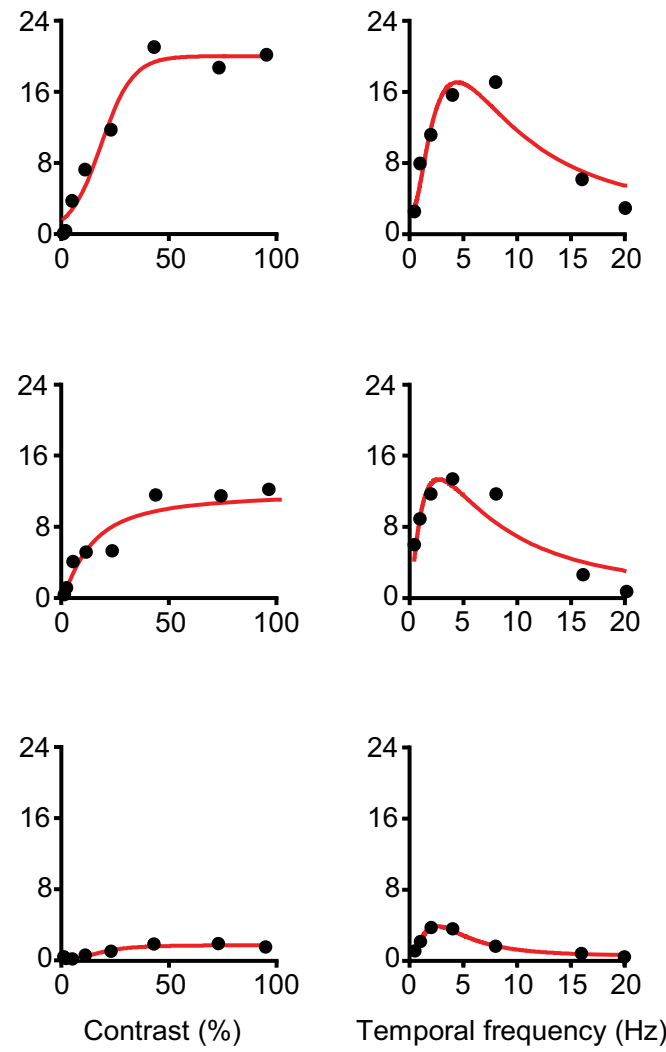

Figure 3. Representative RF properties of short-, medium-, and long-latency CG neurons. $\boldsymbol{A}-\boldsymbol{C}$, RF maps, plotted using reverse correlation (red represents ON; blue represents OFF responses), and the orientation/direction, spatial frequency, contrast tuning, and temporal frequency tuning curves for three example (G neurons, with short (3.0 ms), medium (14.8 ms), and long ( 35.0 ms) antidromic latencies.

tribution of antidromic latencies for these three subpopulations. Although the distributions of the visually responsive and visually unresponsive CG neurons overlapped substantially, visually unresponsive CG cells had significantly longer antidromic latencies than visually responsive CG neurons (mean: $30.33 \pm 1.9 \mathrm{~ms}$ vs
$19.04 \pm 1.67 \mathrm{~ms}$, Mann-Whitney $U$ test, $p<0.001)$. The extreme ends of the distribution were especially noteworthy; whereas all 7 visually tested CG neurons with antidromic latencies of $<5 \mathrm{~ms}$ (corresponding to conduction velocities of $>3.4 \mathrm{~m} / \mathrm{s}$ ) were visually responsive, all of the 6 visually tested CG neurons with anti- 
A

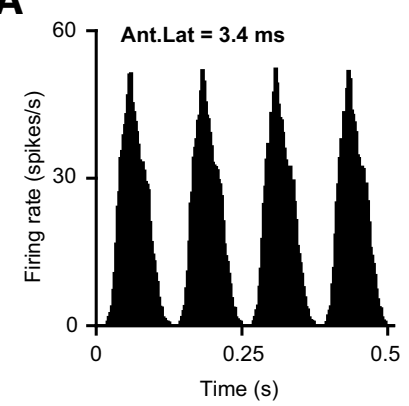

C

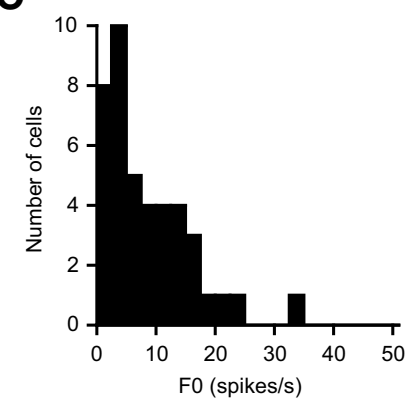

E

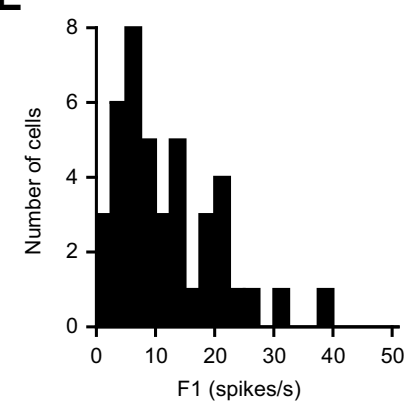

G

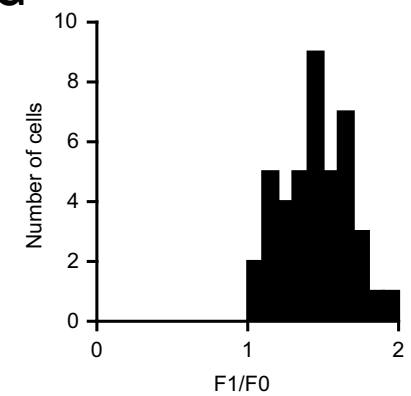

B

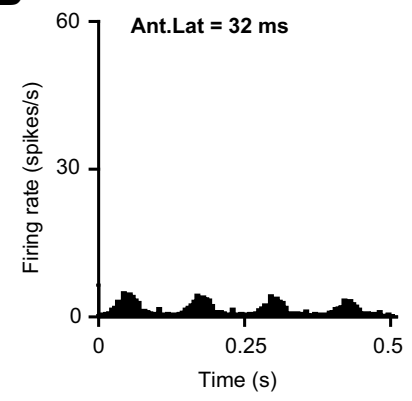

D

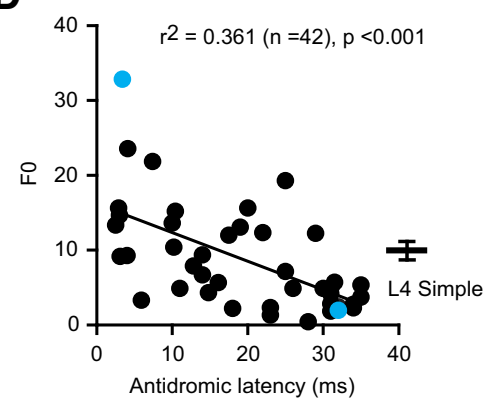

$\mathbf{F}$

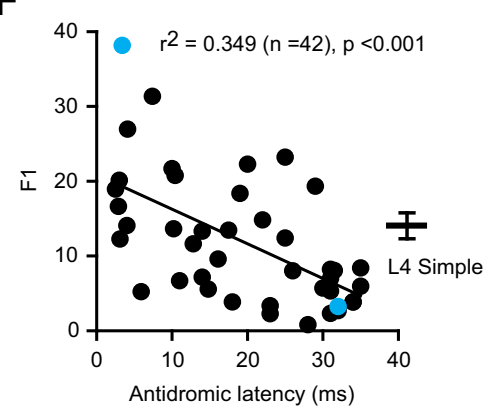

H

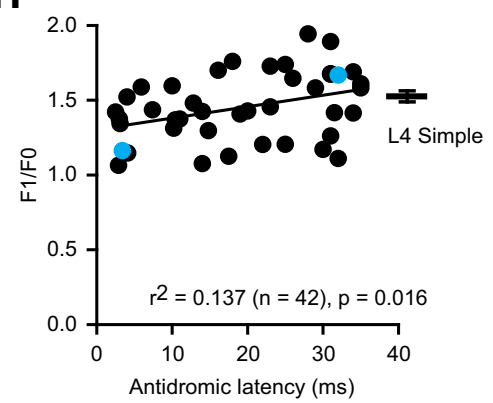

Figure 4. CG neurons with fast-conducting axons are more responsive to visual stimuli. $A, B$, PSTHs for two example CG neurons during optimal drifting grating stimulation at the preferred orientation, temporal frequency, and spatial frequency. These neurons had antidromic latencies of $3.4 \mathrm{~ms}(\boldsymbol{A}, \mathrm{F} 1=38.1$ spikes $/ \mathrm{s})$ and $32 \mathrm{~ms}(\boldsymbol{B}, \mathrm{F} 1=4.2$ spikes $/ \mathrm{s})$ and are the same example neurons presented (below) at the top of Figures 5-9, and in the scattergrams (blue dots) in Figures $4-10,13,14$. Frequency distribution of F0 ( $($ ) and F1 $(\boldsymbol{E})$ amplitude observed during optimal stimulation for all visually responsive $(G$ neurons. $\boldsymbol{D}, \boldsymbol{F}$, Relationship between maximal F0 (D) and F1 $(\boldsymbol{F})$ during optimal visual stimulation for visually responsive ( $G$ neurons and antidromic latency. Visual responsiveness was significantly related to antidromic latency for both $\mathrm{F} 0(p<0.001)$ and $\mathrm{F} 1(p<0.001)$. G, Frequency distribution of F1/F0 ratio for all visually responsive $G$ neurons. $\boldsymbol{H}$, Relationship between F1/F0 ratio values and antidromic latency for all visually responsive $C G$ neurons. $\boldsymbol{D}$, $\boldsymbol{F}, \boldsymbol{H}$, For comparative purposes, horizontal bar (to right of scattergrams) represents mean \pm SE values for F0, F1, and F1/F0 ratios, respectively, for L4 simple cells of awake rabbit V1 (from Zhuang et al., 2013).

dromic latencies of $>40 \mathrm{~ms}$ (corresponding axonal conduction velocities of $<0.43 \mathrm{~m} / \mathrm{s}$ ) were visually unresponsive. Figure $2 A 2$ shows the population averages of the three groups of CG neurons. For comparative purposes, we also show the antidromic latencies of a population of $>100$ rabbit LGN geniculocortical neurons (Fig. 2A3) (Swadlow and Weyand, 1985), which are much more rapidly conducting (median conduction velocity of $17.9 \mathrm{~m} / \mathrm{s}$, range: $6-37.8 \mathrm{~m} / \mathrm{s}$ ).

It should be emphasized that visually unresponsive CG neurons (1) were extensively tested with a very wide variety of hand-controlled and computer-generated stimuli and (2) they were tested in both alert and nonalert brain states (conditions that affect thalamic and cortical responsiveness) (Cano et al., 2006; Zhuang et al., 2014); and (3) we knew the retinotopy of the tissue under study because other neurons in the penetration (often simultaneously studied at the same location) were visually responsive. We were able, therefore, to test these cells very carefully for visual responsiveness.

Each of the 42 visually responsive CG neurons had a simple RF, as defined by the presence of one or more spatially separated ON and/or OFF subfields (as in Zhuang et al., 2013). Most 37 of 42 had only a single subfield (S1, $26 \mathrm{ON}$ and 11 $\mathrm{OFF}$ ) and the remainder had an $\mathrm{ON}$ and an OFF subfield (S2). However, by applying a threshold of $30 \%$ (to remove noise; see Materials and Methods), we may have cut off some very weak subfields and thereby underestimated the population of simple cells with $>1$ subfield. When tested with an optimal drifting grating stimulus, all of these cells had an F1/F0 ratio of $>1$ (mean: $1.45 \pm 0.04$ ), which is a characteristic feature (sometimes considered a defining feature) of simple cells in cats and monkeys (Skottun et al., 1991). Notably, all 42 of these simple CG neurons responded in a sustained manner (when tested in the alert state) (see Materials and Methods; see Fig. 9) to an optimally oriented and positioned stationary stimulus of appropriate sign (light or dark) placed over the RF.

Spontaneous firing rates of CG neurons were very low, and Figure $2 B$ shows their distribution for visually responsive and visually unresponsive CG neurons (and, for comparative purposes, for the same corticotectal neurons shown in Fig. 1). Clearly, both CG populations had much lower rates than the corticotectal neurons (nonoverlapping, except for two cells). Visually unresponsive CG neurons had extremely low spontaneous firing rates. All were $<0.5$ spikes/s (mean: $0.03 \pm 0.09$ spikes/s), and most were never observed to fire spontaneously. Visually responsive CG neurons also exhibited very low spontaneous firing rates (median firing rate: 0.19 spikes/s, mean firing rate: $0.45 \pm 0.14$ spikes/s, range: $0-3.14$ spikes/s, $p$ values for all three compared groups $<$ 0.001, Mann-Whitney $U$ test). 
All visual testing to ascertain the relationship between axonal conduction time and visual response properties were done using stimuli which were optimally tuned to a number of variables. Spatiotemporal RF maps were generated from reverse correlation from the sparse noise stimulation. Then a drifting grating was centered over the RF and optimal tuning to orientation, size, spatial frequency, temporal frequency, and contrast were independently tested to determine optimal values. Figure 3 shows data from three representative CG neurons: one fast-conducting (top, antidromic latency $=3.0 \mathrm{~ms}$ ), one medium-conducting (middle, antidromic latency $=14.8 \mathrm{~ms}$ ), and one slowly conducting (bottom, antidromic latency $=35$ $\mathrm{ms})$. For each of these cells, the spatial RF, orientation tuning, spatial frequency tuning, contrast response function, and temporal frequency tuning are shown.

\section{Visual response properties and axonal conduction time}

Amplitude of the visual response

PSTHs generated from optimal drifting grating stimuli for two example visually responsive CG neurons with short $(3.4 \mathrm{~ms}$, left) and long (32.0 ms, right) antidromic conduction latencies can be seen in Figure $4 A, B$. These two example neurons were chosen both because of their nearextreme positions on the axonal conduction time spectrum and because they were both studied very thoroughly ( $>3 \mathrm{~h}$ each). They were assessed for most of our visual tests (see Figs. 4-10) and tests for state dependence (see Figs. 13, 14), and their values are presented as the blue dots in those figures.

The unmodulated response (F0) and the modulated responses (F1) were measured from the PSTHs generated by optimal grating stimulation. The amplitude of the F0 response for visually responsive CG neurons values ranged from 0.4 to 32.8 spikes/s (mean: $8.72 \pm 1.08$ spikes/s), and the distribution of F0 amplitudes can be seen in Figure $4 C$. The relationship between $\mathrm{F} 0$ during optimal grating stimulation and axonal conduction time can be seen in Figure $4 D$. Visually driven F0 amplitudes were strongly related to antidromic conduction time such that CG neurons with fast-conducting axons (short antidromic latencies) had higher response amplitudes $\left(r^{2}=-0.361\right.$, $p<0.001)$. The amplitude of the F1 response for visually responsive CG neurons values ranged from 0.8 to 38.1 spikes/s (mean: $11.89 \pm 1.33$ spikes/s), and the distribution of F1 amplitudes can be seen in Figure $4 E$. The relationship between F1 during optimal grating stimulation and axonal conduction time can be seen in Figure $4 F$. Visually driven $\mathrm{F} 1$ amplitudes were strongly related to conduction time such that CG neurons with fast-conducting axons had higher response amplitudes $\left(r^{2}=0.349, p<0.001\right)$. Response linearity was quantified by calculating the F1/F0 ratio, electrical stimulation.
enon terminal within
B

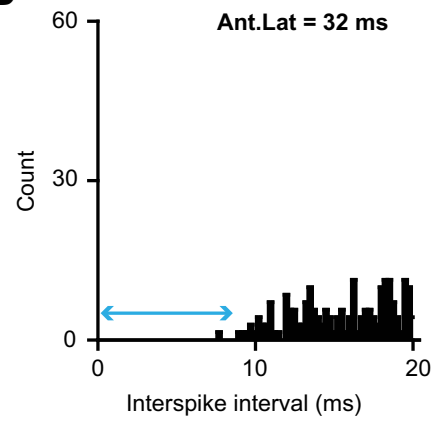

D

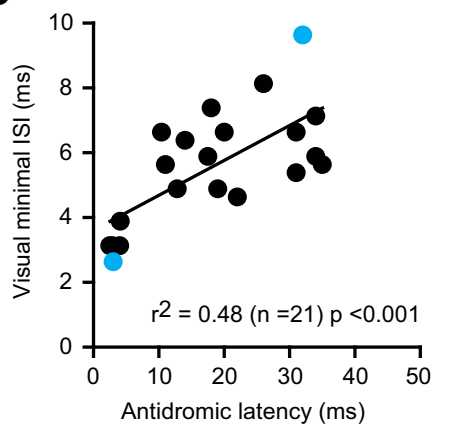

F

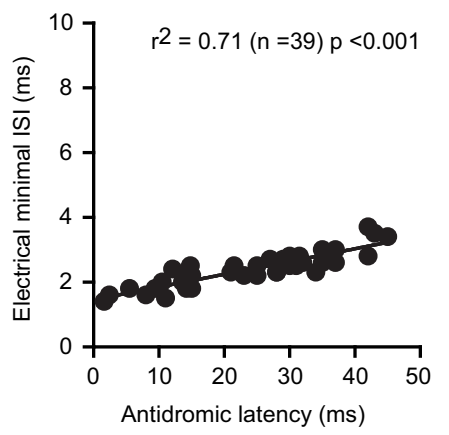

Figure 5. CG neurons with fast-conducting axons have shorter visually driven and electrically elicited interspike intervals. $\boldsymbol{A}, \boldsymbol{B}$, The interspike interval distribution obtained during optimal drifting grating stimulation for the fast-conducting $(\boldsymbol{A})$ and sow-conducting $(\boldsymbol{B}) C G$ neurons seen in Figure $4 A, B$, respectively. Blue arrows indicate minimal interspike interval. $\boldsymbol{C}$, Frequency (reciprocal) for each (G neuron and the minimal interspike interval. $\boldsymbol{D}$. The relationship between antidromic latency and

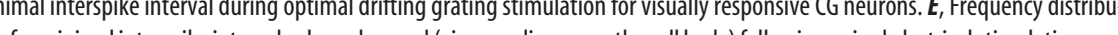
tion for minimal interspike interval values observed (via recordings near the cell body) following paired electrical stimulation nea

and the distribution of ratios can be seen in Figure $4 G$. Although all CG neurons had F1/F0 ratios of $>1.0$ (signifying response linearity), there was a significant positive relationship between axonal conduction time and the F1/F0 ratio $\left(r^{2}=0.137, p=\right.$ 0.016 ), such that visually responsive CG neurons with slower conducting axons had a slightly higher F1/F0 ratio than those with faster conducting axons.

Visually and electrically elicited minimal interspike intervals Interspike interval distributions were calculated for visually responsive neurons with an optimal drifting grating that was presented over the RF center for at least $10 \mathrm{~min}$. The resulting interspike interval distributions for the example fast and slowly conducting CG neurons illustrated in Figure $4 A, B$, are shown in Figure $5 A$ and Figure $5 B$, respectively. The shortest visually driven interspike intervals seen in these distributions for each cell 
A

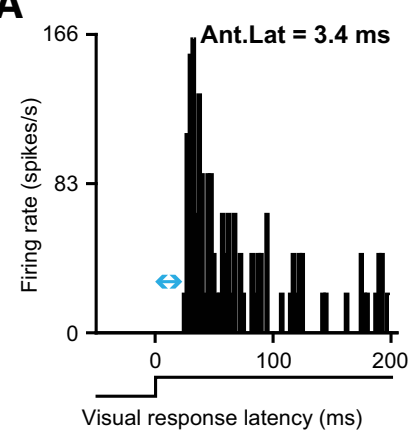

C

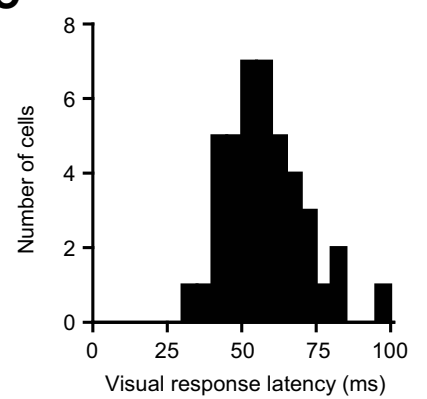

B

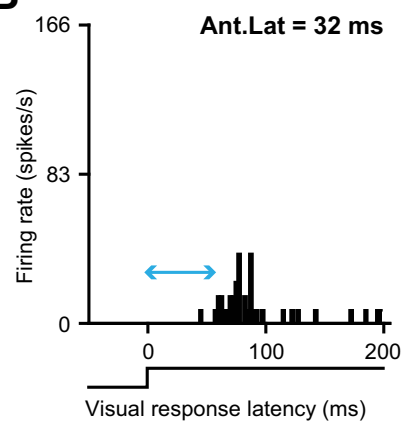

D

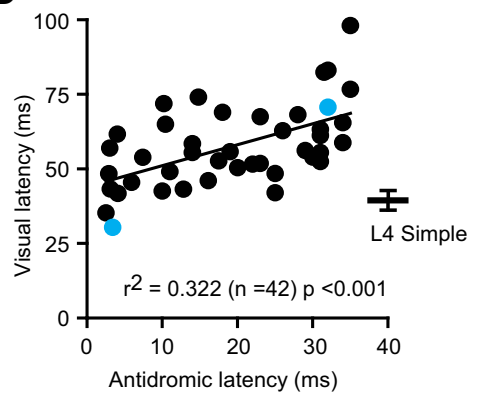

Figure 6. CG neurons with fast-conducting axons have shorter visual response latencies than $C G$ neurons with slow-conducting axons. $\boldsymbol{A}, \boldsymbol{B}$, PSTHs to flashing ( 2 s on, 2 s off) visual stimuli (for the same two example (G neurons shown in Figs. 4, 5A, $B$ ) showing the first $200 \mathrm{~ms}$ after stimulus onset. Blue arrows indicate response latency. $\boldsymbol{C}$, Frequency distribution of the response latency to flashing stimuli as measured from the PSTH for visually responsive CG neurons. D, Relationship between antidromic latency and visual response latency to flash for visually responsive CG neurons. Right, Horizontal bar represents mean \pm SE for visual response latency for L4 simple cells of awake rabbit V1 (from Zhuang et al., 2013).

(the minimal interspike interval, blue arrows) is much shorter for the fast-conducting axon. For all cells, the values of such visually driven minimal interspike intervals ranged from 2.7 to $9.6 \mathrm{~ms}$ (mean: $5.6 \pm 0.4 \mathrm{~ms}$ ), and the distribution of minimal interspike intervals for all visually responsive CG neurons can be seen in Figure $5 C$. Axonal conduction time was significantly related to minimal interspike interval (Fig. $5 D ; r^{2}=0.48, p<0.001$ ) such that visually responsive CG neurons with fast-conducting axons have shorter minimal interspike intervals. Moreover, the minimal interspike interval of a cell was strongly related to, but much shorter than, the reciprocal of the maximum firing rates (Fig. $5 C$, inset, $\mathrm{F} 1$ values) generated during visual stimulation $\left(r^{2}=0.379, p=\right.$ 0.003). It is important to note that the minimal visually driven interspike intervals are related to, but are considerably longer than, the minimal interspike intervals evoked by electrical stimulation of the axons. Thus, for a different set of 35 CG neurons (the visually untested CG neurons shown in Fig. 2A1), we measured the minimal interspike intervals elicited by electrical stimulation (elicited by two stimuli delivered near the terminals of CG axons in the LGN), at intervals near the refractory period (Kocsis et al., 1979; Swadlow, 1985). The minimal interspike interval values elicited by electrical stimulation ranged between 1.4 and $3.4 \mathrm{~ms}$ (distribution in Fig. $5 E$ ) and, like the minimal interspike intervals elicited by visual stimulation (above), they were strongly related to axonal conduction time (Fig. $5 F ; r^{2}=0.787, p<$ $0.001)$. However, the minimal interspike interval values elicited by electrical stimulation are $<1 / 2$ of the minimal interspike intervals elicited by visual stimulation (compare Fig. $5 D, F$ ).

Visual response latency

To measure the time course of visually evoked responses, flashing bars ( $2 \mathrm{~s}$ on, $2 \mathrm{~s}$ off), optimized to the tuning preferences of each bution of C-50 values can be seen in Figure $7 \mathrm{C}$ and ranged from 5.7\% to $64.5 \%$ (mean: $28.9 \pm 2.5 \%$ ). Axonal conduction time was significantly related to C-50 values $\left(r^{2}=0.129, p=0.023\right)$ such that CG neurons with fast-conducting axons were somewhat more sensitive to lower contrast values (lower C-50 values). Only 6 of the 42 CG cells that were tested for contrast response functions showed evidence of high-contrast suppression (see Materials and Methods), and this property was not significantly related to axonal conduction time $\left(\chi^{2}, p=0.586\right)$.

\section{Temporal frequency tuning}

Temporal frequency tuning was tested from 0.5 to $20 \mathrm{~Hz}$, and tuning curves were fitted with Gaussian functions. The temporal frequency turning curves from our fast and slowly conducting example CG neurons are shown in Figure $7 E$ and Figure $7 F$, respectively. From the Gaussian fits, we measured the preferred temporal frequency, and the temporal frequency bandwidth. Preferred temporal frequency values ranged from 0.75 to $5.70 \mathrm{~Hz}$ (mean: $3.0 \pm 0.2 \mathrm{~Hz}$ ), and the distribution of these values can be seen in Figure 7G. Significant positive correlation was observed between axonal conduction time and preferred temporal frequency (Fig. $7 H ; r^{2}=0.213, p=0.002$ ) such that visually responsive CG neurons with fast-conducting axons preferred faster stimuli.

\section{Orientation and directional selectivity}

Orientation/directional tuning was tested every 15 or every 30 degrees, and tuning curves were fitted with von Mises functions. Example orientation tuning curves from our fast and slowly conducting example CG neurons are seen in Figure $8 A$ and Figure $8 B$, respectively. From the fits, we measured the OSI and DSI. OSI values ranged from 0.27 to 1.0 (mean: $0.77 \pm 0.03$ ), and the 
A

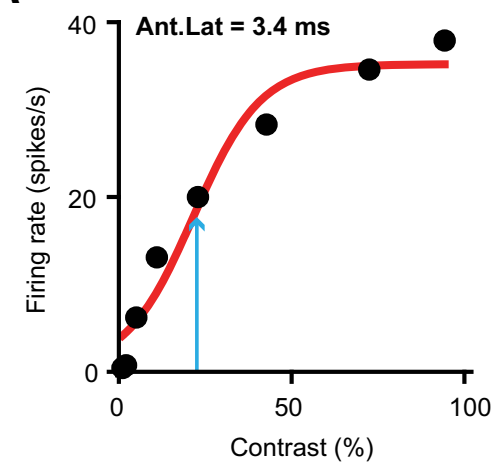

C

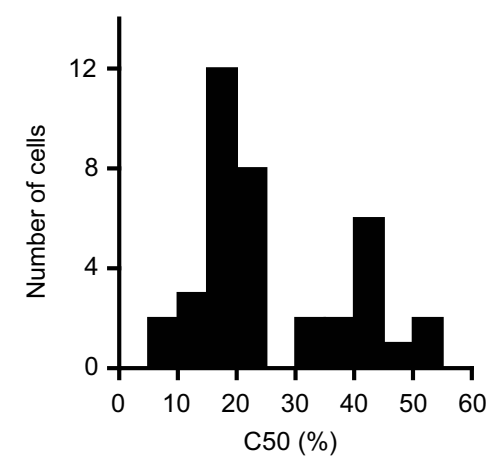

E

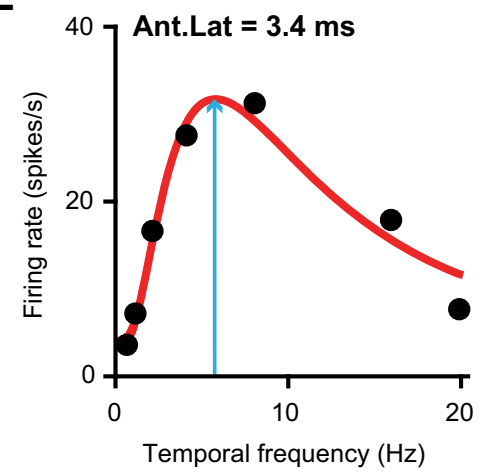

G

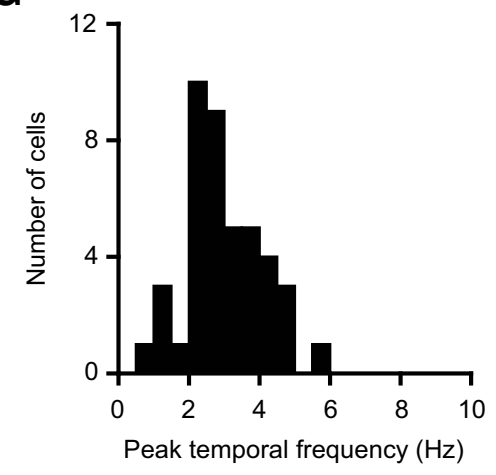

B

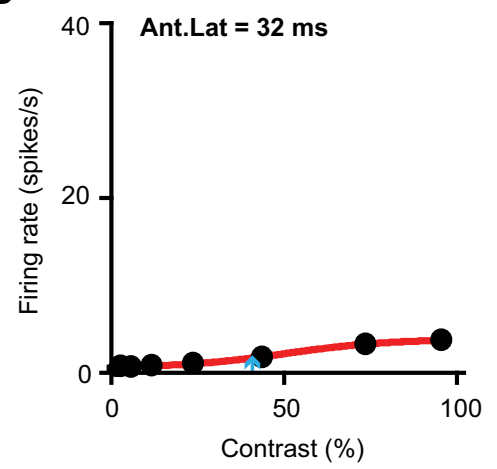

D

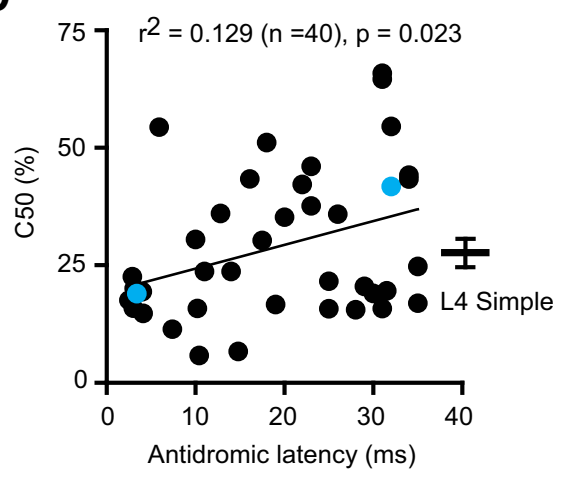

$\mathbf{F}$

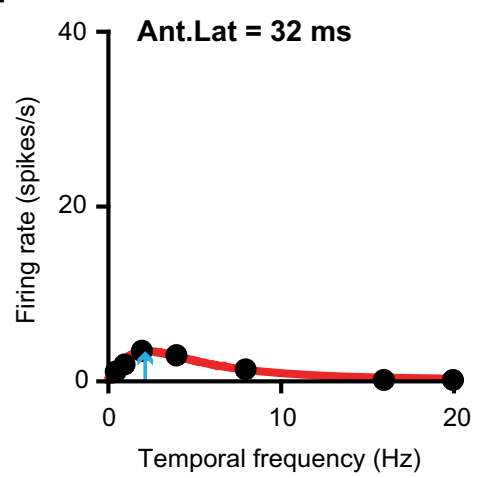

H

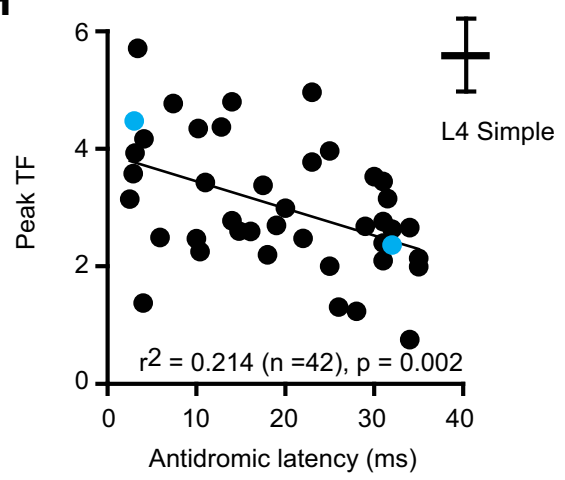

Figure 7. CG neurons with fast-conducting axons respond better to lower contrast or faster moving stimuli than CG neurons with slowly conducting axons. $A-D$, Contrast response functions were obtained and fit with a hyperbolic model (see Materials and Methods). $\boldsymbol{A}, \boldsymbol{B}$, Contrast response functions for the two example visually responsive CG neurons (the same fast and slow CG neurons as shown in Figs. $4-6)$. Blue arrows indicate $(-50$ values. C, Frequency distribution of $C-50$ values for visually responsive CG neurons. D, Relationship between antidromic latency and C-50 for visually responsive C neurons. $\boldsymbol{E}-\boldsymbol{H}$, Temporal frequency tuning was measured by testing grating speeds between 0.5 and $20 \mathrm{~Hz}$, and responses were fit with a Gaussian function. $\boldsymbol{E}, \boldsymbol{F}$, Example temporal tuning functions for the two example visually responsive CG neurons. Blue arrows indicate peak temporal frequencies. G, Frequency distribution of peak temporal frequencies for visually responsive CG neurons. $\boldsymbol{H}$, Relationship between

distribution of these values can be seen in Figure 8C. Axonal conduction time was not significantly related to the OSI (Fig. $\left.8 D ; r^{2}=0.011, p=0.495\right)$. DSI values ranged from 0.03 to 0.95 (mean: $0.43 \pm$ 0.05 ), and the distribution of these values can be seen in Figure $8 E$. There was a significant positive relationship between axonal conduction time and the directional selectivity index (Fig. $8 F ; r^{2}=0.291, p<$ 0.001 ), such that visually responsive CG neurons with slow-conducting axons were less selective for stimulus direction.

\section{Sustained responding}

As noted above, all 42 CG neurons that were visually driven generated a sustained response to a maintained stationary stimulus of optimal size and appropriate contrast ( $2 \mathrm{~s}$ on, $2 \mathrm{~s}$ off). Because the sustained component of visual responses is highly sensitive to brain state (Swadlow and Weyand, 1985, 1987; Bezdudnaya et al., 2006) (Fig. $9 F$ ), such testing was done in the alert state (during periods of EEG arousal). Figure 9A, $B$ illustrates the PSTHs of the fast-conducting and slowly conducting example CG neurons to presentation of this maintained, stationary stimulus (with raster plots shown in the insets), and Figure $9 C$ shows the population response of all 42 visually responsive CG neurons (normalized to the peak amplitude of the transient component of the response, mean number of stimulus presentations: $25.7 \pm 3.4$ ). There was no significant relationship between axonal conduction latency and either (1) the magnitude of the sustained response (Fig. 9D, Sustained Index; see Materials and Methods) $\left(r^{2}=\right.$ $0.001, p=0.973)$, or (2) the Transient/ Sustained ratio (Fig. 9E; $r^{2}=0.043, p=$ $0.179)$. Finally, Figure $9 F$ illustrates why such testing is done in the alert state. Here we show the population response of 21 CG neurons that were studied in both states (mean number of stimulus presentations $=29.0 \pm 3.6$ alert, $39.7 \pm 8.4$ nonalert). Responses are normalized to the peak amplitude of the transient response when alert. When nonalert, the initial transient response is reduced by $\sim 13 \%$ ( $p=0.026$, Wilcoxon signed rank test). However, a much greater reduction is seen in the sustained response (reduced by $\sim 48 \%, p<0.001$, Wilcoxon signed rank test). responsive CG neurons. $\boldsymbol{D}, \boldsymbol{H}$, Right, Horizontal bars represent mean $\pm S E$ for $C-50$ and peak temporal frequency values for L4 simple cells of awake rabbit V1 (from Zhuang et al., 2013). 
A

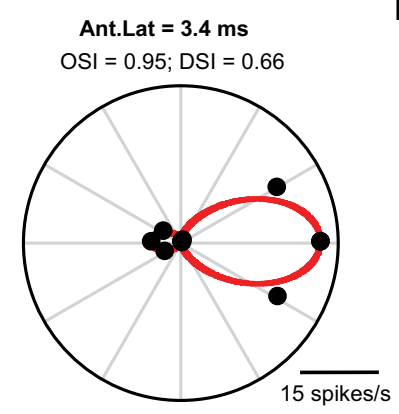

B

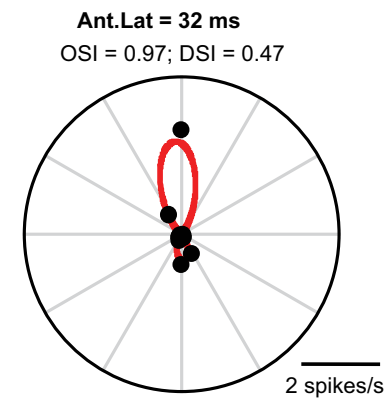

C

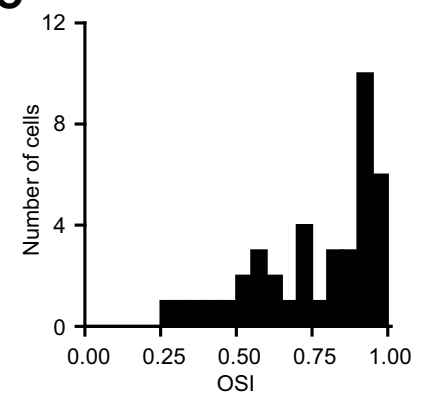

E

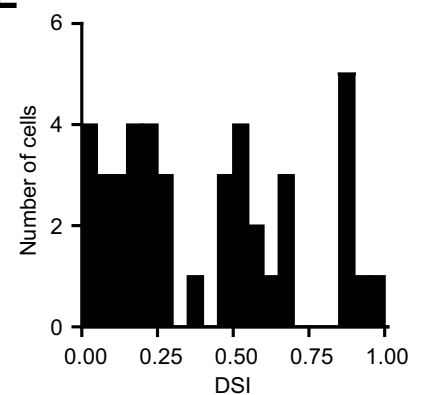

D

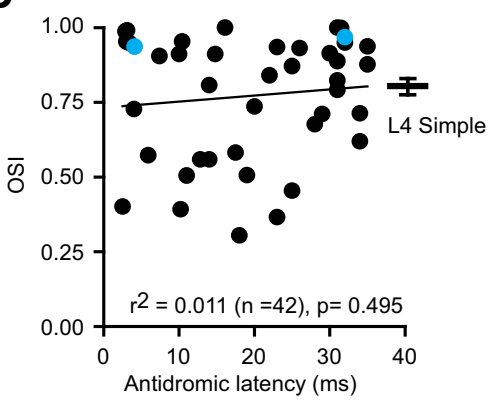

F

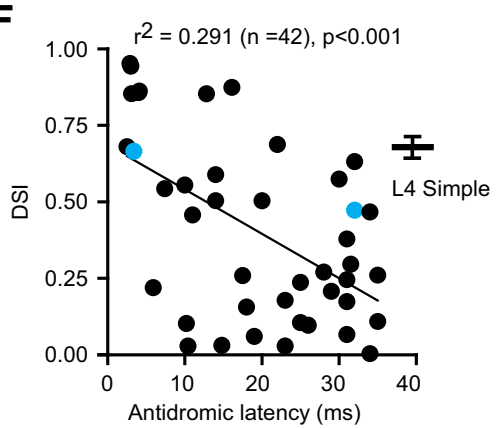

Figure 8. Fast and slow CG neurons show similar orientation tuning, but fast-conducting CG neurons are more directionally selective. $\boldsymbol{A}-\boldsymbol{D}$, Orientation tuning curves were obtained and fit with a von Mises function (see Materials and Methods). $\boldsymbol{A}, \boldsymbol{B}$, Orientation tuning curves for our example fast-conducting (antidromic latency $=3.4 \mathrm{~ms}$ ) and slowly conducting (antidromic latency $=32 \mathrm{~ms}$ ) $C \mathrm{G}$ cell. C, Frequency distribution of OSI values for visually responsive CG neurons. D, Relationship between antidromic latency and OSI values. $\boldsymbol{E}$, Frequency distribution of DSI values for these cells. $\boldsymbol{F}$, Relationship between antidromic latency and DSI values. $\boldsymbol{D}, \boldsymbol{F}$, Right, Horizontal bar represents mean \pm SE for OSI/DSI values for L4 simple cells of awake rabbit V1 (from Zhuang et al., 2013).

Spatial frequency preference and response reliability

Spatial frequency tuning curves were measured (Fig. $10 A, B$ ) and fit with a Gaussian function. From the fits, the preferred spatial frequency value was obtained. Preferred spatial frequency values ranged from 0.08 to $0.81 \mathrm{cpd}$ (mean: $0.22 \pm 0.03 \mathrm{cpd}$ ), and axonal conduction time had no significant relationship with preferred spatial frequency $\left(r^{2}=0.032, p=0.254\right)$. Response variability was calculated as the Fano factor (Fig. 10C,D), which was measured (for visually responsive neurons) with an optimal drifting grating presented over the receptive center for at least $10 \mathrm{~min}$. Fano factor values ranged from 0.21 to 1.79 (mean: $1.09 \pm 0.06$ ), and axonal conduction time was not significantly related to this measure $\left(r^{2}=0.005, p=0.667\right)$.

Tests for bimodality

Hartigan Dip Tests revealed no evidence for bimodal distributions in any of the above measures that we tested (antidromic latency, $p=0.23$; spontaneous firing rate, $p=0.98 ; \mathrm{F} 1 / \mathrm{F} 0$ ratios, $p=0.38$; $\mathrm{F} 1, p=0.87 ; \mathrm{F} 0, p=0.75$; visual minimal interspike interval, $p=$
0.188 ; electrical minimal interspike interval, $p=0.55$; visual latency, $p=0.91$; C-50, $p=0.66$; peak temporal frequency, $p=0.98$; 0SI, $p=0.095$; DSI, $p=0.37$; peak spatial frequency, $p=0.85$; Fano factor, $p=0.94$; depth, $p=0.94$ ).

\section{Sublaminar depth distribution of CG neurons}

For 45 visually tested CG neurons (27 visually responsive, 18 visually unresponsive), the depth from the reversal point of the flash-evoked potential (as in Fig. $1 A, B)$ was measured. Figure $11 A$ shows the depth distribution of visually responsive and visually unresponsive CG neurons of different antidromic latencies. Antidromic latency was significantly related to the cortical depth below the flash reversal point $\left(r^{2}=0.172, p<0.005\right)$. Whereas the faster conducting CG neurons were all found superficially $(<1200$ $\mu \mathrm{m}$ from the reversal depth), CG neurons with slowly conducting axons $(>22 \mathrm{~ms}$ antidromic latency, very likely unmyelinated along most of their length; see Materials and Methods) were located both superficially and deep within L6.

Because depth within L6 was so strongly related to axonal conduction time, we asked whether the strong relationship between conduction time and visual responsiveness might be more related to depth than to conduction time. To examine this, we looked only at superficial, visually responsive CG neurons, located from 800 to $1200 \mu \mathrm{m}$ beneath the flash reversal point, and we examined the relationship between visual response amplitude ( $\mathrm{F} 1$ values) and conduction latency (as in Fig. $4 F$ ). Figure $11 B$ shows that the effect of conduction velocity on F1 during optimal visual stimulation was still present when we limited the analysis to only the superficial CG neurons $\left(r^{2}=0.279\right.$, $p=0.014)$.

Another way to approach this question (Fig. 11C) is to limit the analysis to the most slowly conducting CG neurons (antidromic latencies of $>22 \mathrm{~ms}$ ) and to compare the properties of those found superficially within L6 (800-1200 $\mu \mathrm{m}$ beneath the reversal point) with those found deeper within L6 $(>1200 \mu \mathrm{m}$ beneath the reversal point). We found no difference in the magnitude of the visual response for these populations of slowly conducting CG neurons (F1 superficial: $8.0 \pm 2.24$ spikes/s, F1 deep: $8.02 \pm 2.96$ spikes $\left./ s, r^{2}=0.001, p=0.952\right)$.

Effects of awake brain state transitions on the visual response properties of CG neurons

We examined CG neurons for the effects of alert/nonalert brain state on several of the response properties that we previously examined for brain state effects in L4 spiny cells of rabbit V1 (Zhuang et al., 2014), using these same methods of data segmentation by brain state. Thus, although data presented above (except for Fig. 9F) were obtained during a natural mix of awake 
A

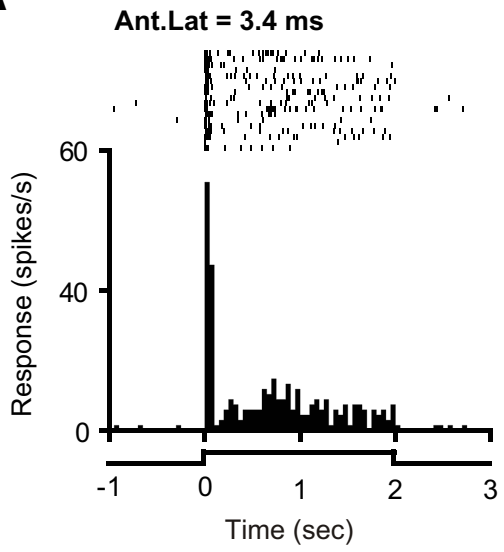

D

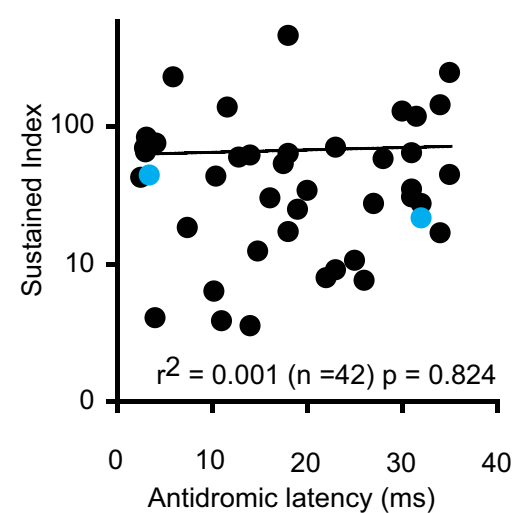

B

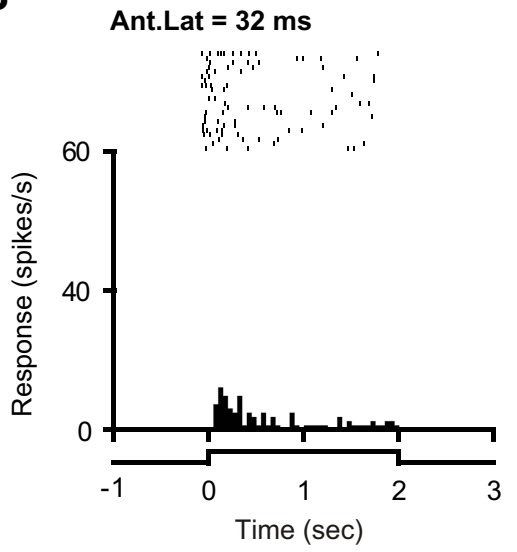

E

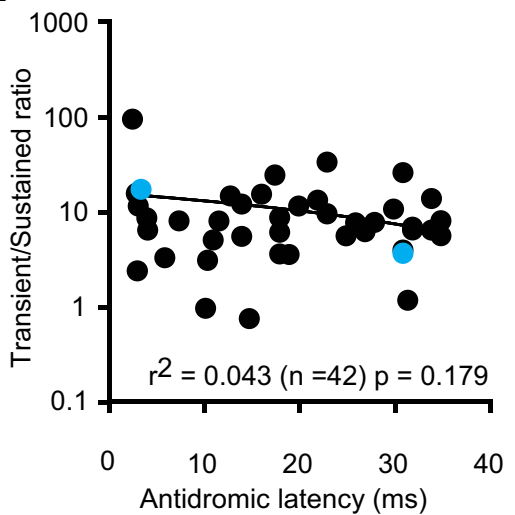

C

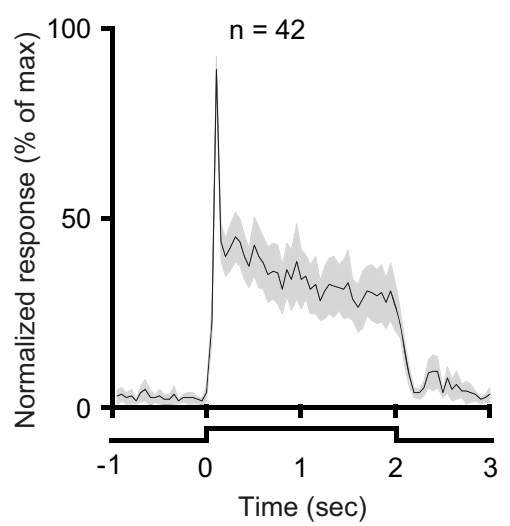

F

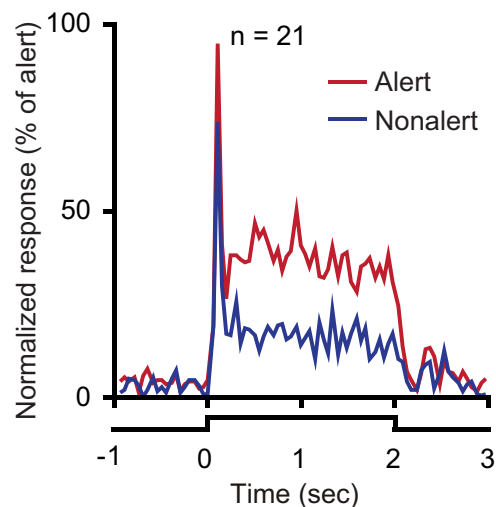

Figure 9. All CG neurons responded in a sustained manner to a maintained stationary flashing visual stimulus. $\boldsymbol{A}, \boldsymbol{B}$, PSTHs (insets, raster plots) showing response to a stationary optimal flashing stimulus presented over the RF center from the two example visually responsive CG neurons (the same fast and slow CG neurons shown in Figs. 4 -8). C, Mean PSTH calculated from population of CG neurons, normalized to the peak amplitude of the transient component. Shaded area represents mean \pm SEM for each bin. $D$, Relationship between antidromic latency and the "sustained index," a measure of the amplitude of the sustained response (see Materials and Methods). $\boldsymbol{E}$, Relationship between antidromic latency and the "transient/sustained ratio" (see Materials and Methods). $\boldsymbol{F}$, PSTHs of the population responses of CG neurons, measured in both alert (red) and nonalert (blue) states. Data from each cell are normalized to the peak amplitude of the transient component of the response when alert. The transient component is little affected by brain state, but the sustained component is strongly depressed when nonalert.

states, here, we segregate data files into alert and nonalert segments, and pool those segments for analysis (see Materials and Methods). Figure 12 (top four traces) shows one transition from the alert to the nonalert state. An optimal drifting grating (top) stimulus elicits spikes in a CG neuron. Rate and reliability of the visually driven spikes change abruptly at the transition between nonalert and alert brain states (see hippocampal and cortical EEG). Eye position was monitored (at $30 \mathrm{~Hz}$ ) by infrared camera (snapshots shown at $1 \mathrm{~s}$ intervals). The PSTHs below are derived from $5 \mathrm{~s}$ periods before and after many such transitions (120 stimulus cycles when alert, and 129 cycles when nonalert).

Response amplitude. Figure 13A1 compares the F1 response of all studied CG neurons with such alert/nonalert state shifts. Testing was done using a near-optimal sinusoidal drifting grating stimulus. At least 40 stimulus cycles were presented in each state (mean alert vs nonalert: $248.8 \pm 33.7$ cycles vs $295.5 \pm$ 40.4 cycles). Every CG cell tested $(N=25)$ showed an enhanced response amplitude in the alert state. Figure $13 A 2$ shows, for the CG cells shown in Figure 13A1, the population response for F1 values in each state (mean alert vs nonalert: $21.98 \pm 2.29$ spikes/s vs $12.97 \pm 2.05$ spikes/s, $p<0.001$, Wilcoxon signed rank test). Figure 13A3 (left) shows the same data presented in Figure 13A1, plotted as the mean F1 response in the alert state, relative to the F1 when nonalert (which would equal 100\%). A mean increase of $87 \%$ (i.e., alert $=187 \%$ of nonalert; Fig. $13 \mathrm{~A} 3$ ) was seen for $\mathrm{CG}$ neurons in the alert state. For comparative purposes, Figure $13 \mathrm{A3}$ (right) shows this same measure, but for L4 simple cells (derived by reanalysis of data in Zhuang et al., 2014). This comparison shows that the effect of state on the F1 response was somewhat greater in the CG neurons than in the L4 simple cells, but this difference was not statistically significant (Mann-Whitney $U$ test, $p=0.104)$.

Response reliability. Similarly, response reliability (as measured by Fano factor), was very strongly affected by alert/nonalert state shifts. Figure $13 B 1$ compares the Fano factor of all studied CG neurons to such alert/nonalert state shifts. The same dataset (and same number of stimulus cycles) used to obtain Figure 13A, using near-optimal sinusoidal drifting grating stimulation, was used for this analysis. Every CG cell tested $(N=25)$ showed a decreased Fano factor (enhanced reliability) in the alert state. Figure $13 B 2$ shows, for the CG cells shown in Figure 13B1, the population response for Fano factor values in each state (mean alert vs nonalert: $0.62 \pm 0.06$ vs $1.52 \pm 0.11, p<0.001$, Wilcoxon signed rank test). Figure $13 \mathrm{B3}$ (left) shows the same data presented in Figure 13B1, plotted as the mean Fano factor in the alert state, relative to the Fano factor when nonalert (which would equal $100 \%$ ). In the alert state, Fano factor strongly reduced to $41.6 \%$ of its value in the nonalert state. For comparative purposes, Figure $13 B 3$ (right) shows this same measure, but for L4 simple cells (data from Zhuang et al., 2014), and shows a much 
A

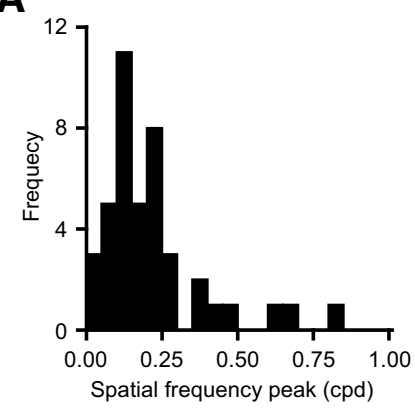

C

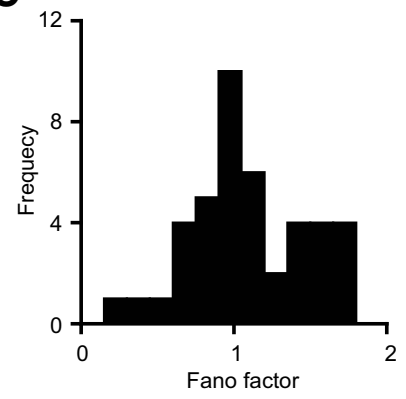

B

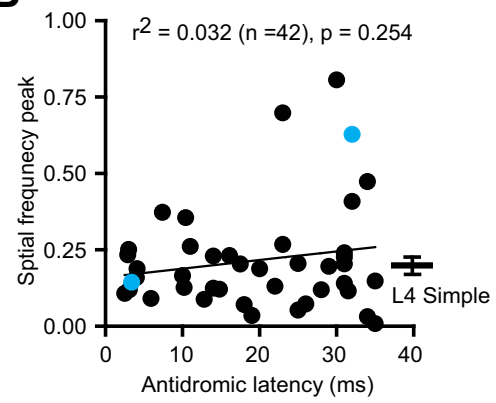

D

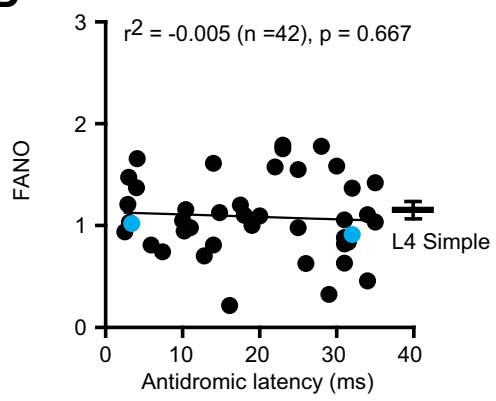

Figure 10. Spatial frequency preference and response reliability are not related to CG antidromic latency. $\boldsymbol{A}$, Frequency distribution of preferred spatial frequencies for visually responsive $C G$ neurons. $\boldsymbol{B}$, Relationship between antidromic latency and preferred spatial frequency. $\boldsymbol{C}$, Frequency distribution of Fano factor values. $\boldsymbol{D}$, Relationship between antidromic latency and Fano factor. $\boldsymbol{B}, \boldsymbol{D}$, Right, Horizontal bar represents mean and SE for spatial frequency and Fano factor values for $L 4$ simple cells of awake rabbit V1 (from Zhuang et al., 2013).

smaller reduction (to $66.7 \%$ of the value in the nonalert state). Thus, the effect of state on the Fano factors was much greater in the L6 CG neurons than in the L4 simple cells, and this difference was highly significant ( $p<0.001$, Mann-Whitney $U$ test).

Measures of Fano factor are sensitive to changes in mean rate (the denominator in the calculation of Fano factor). It is therefore important to verify that the state-dependent changes in Fano factor were not simply an artifact of the reductions in visual response rate that occur in the nonalert state. If this were the case, the decrease in Fano factor with alertness should be strongly related to the increase in response rate. This was not the case, however, as regression analysis revealed only a weak relationship between the magnitude of the state changes in response amplitude and in Fano factor, and this was not statistically significant $\left(r^{2}=0.063, p=0.22\right)$. It should also be noted that axonal conduction time was not related to Fano factor (Fig. 10D) despite being strongly related to response rate.

Similarly, because alertness increased visual response amplitude slightly more in L6 CG neurons than in L4 simple cells (Fig. $13 A 3)$, it could be argued that the larger increase in rate contributed to the larger reduction in Fano factor seen in L6 CG neurons (Fig. 13B3). To examine this, we equalized the response rates of the L4 simple cells and L6 CG neurons by removing from the dataset, the three CG neurons that showed the greatest staterelated change in response rate. When this was done, the remaining CG neurons showed a lower increase in visual response amplitude with alertness than the L4 simple cells (mean: $67.2 \pm$ $8.9 \%$ for CG neurons vs $68.2 \pm 14.8 \%$ for L4 simple cells). Nevertheless, these CG neurons still showed a much greater staterelated decrease in Fano factor when alert (reduced to $41.3 \%$ of the nonalert value) than did the L4 simple cells (reduced to $66.7 \%$ of the alert value, $p<0.001$, Mann-Whitney $U$ test). This analysis indicates that the greater change in Fano factor seen in L6 CG neurons compared with L4 simple cells is not likely due to greater changes in response rate.

Response latency. Figure $13 \mathrm{C} 1$ compares the visual latencies of CG neurons during alert/nonalert conditions. As in Figure 6, we measured the latency to the initial onset transient, which was not strongly affected by brain state (Fig. 9F). Stimuli used and latency measurements are the same as for the data presented in Figure 6. Seventeen of the 21 cells tested showed a decrease in latency when alert, three cells showed a slight increase in latency, and one cell showed no change. Figure $13 C 2$ shows, for the CG cells shown in Figure $13 C 1$, the mean latency values in each state (mean alert vs nonalert: $56.74 \pm$ $2.56 \mathrm{~ms}$ vs $60.85 \pm 2.66 \mathrm{~ms}, p<0.001$, paired $t$ test). We do not compare these data with L4 simple cells because Zhuang et al. (2014) found no significant state effect for response latency in these cells.

Although the median spontaneous firing rates of CG neurons were very low in both alert (0.01 spikes/s) and nonalert (0.12 spikes/s) states, this difference was statistically significant (mean alert vs nonalert: $0.32 \pm 0.15$ spikes/s vs $0.38 \pm 0.13$ spikes/s, $p=0.04$, Wilcoxon signed rank test). There was little change in the F1/F0 ratio with alertness (mean alert vs nonalert: $1.46 \pm 0.04$ vs $1.50 \pm 0.04, p=0.83$, Wilcoxon signed rank test).

\section{Relationship between CG axonal conduction times and brain state}

We found no interactions between CG axonal conduction times and above effects of brain state. Thus, Figure 14 shows that changes between alert and nonalert brain states had the same effect on optimal F1 responses (A), on Fano factor (B), on visual response latency $(\mathrm{C})$, on the sustained index (D), and on the transient/ sustained ratio $(\mathrm{E})$, regardless of axonal conduction times.

\section{Discussion}

CG axonal conduction times and sensory response properties CG axons were largely slowly conducting, spontaneously silent and, despite testing during alertness, many (42\%) were visually unresponsive. Antidromic latencies ranged from 1.6 to $49 \mathrm{~ms}$ $(\sim 0.35-12.1 \mathrm{~m} / \mathrm{s}$ average velocity between soma and LGN). Axons with mean conduction velocities of $>3.4 \mathrm{~m} / \mathrm{s}$ (antidromic latencies of $<5 \mathrm{~ms}$ ) are very likely to be largely myelinated (Waxman and Bennett, 1972; Waxman and Swadlow, 1976). Notably, only $\sim 10 \%$ of visually tested CG axons fell into this category, and all seven were visually responsive. By contrast, velocities of $<0.8$ $\mathrm{m} / \mathrm{s}$ (antidromic latencies $>22 \mathrm{~ms}$ ) are indicative of unmyelinated central axons (Merrill et al., 1978; Swadlow, 1985; Meeks and Mennerick, 2007; Dellal et al., 2012), and most of these were visually unresponsive. Indeed, none of the six slowest CG neurons responded visually. By contrast, LGN thalamocortical axons of rabbits are overwhelmingly fast-conducting (Fig. 2A3; median axonal conduction velocity $=17.9 \mathrm{~m} / \mathrm{s}$ ), spontaneously active (5-10 spikes/s), and visually responsive (Swadlow and Weyand, 1985; Bezdudnaya et al., 2006; Stoelzel et al., 2008). 
A

- Visually responsive CG $(n=27)$

Visually unresponsive CG $(n=18)$

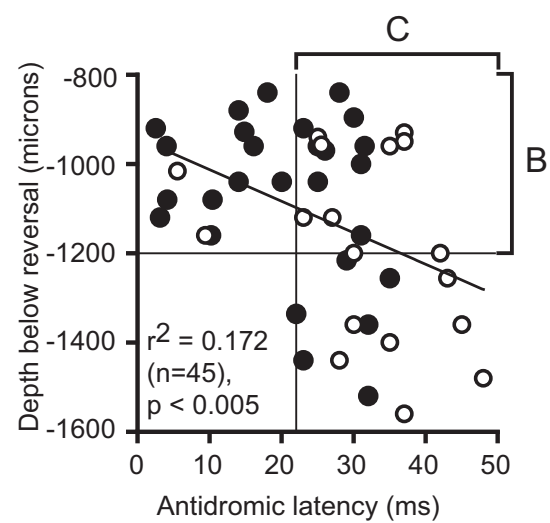

B

Only superficial CG $(800-1200 \mu \mathrm{m})$

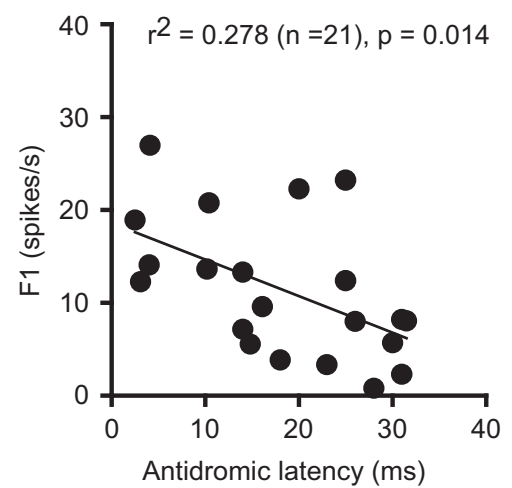

C

Only long latency CG $(22+\mathrm{ms})$

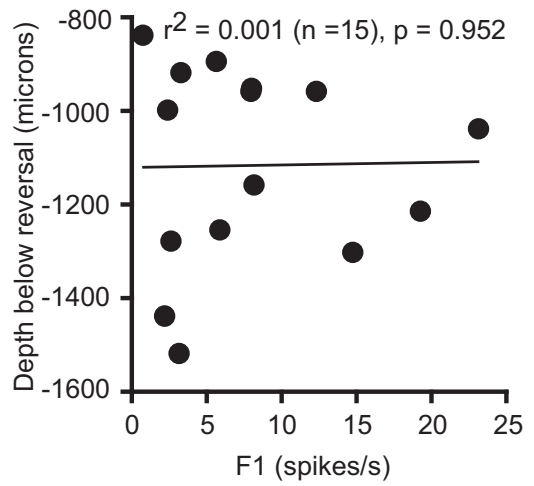

Figure 11. Depth within $\mathrm{L} 6, \mathrm{CG}$ visual responsiveness, and antidromic latency. $A$, Relationship between the depth within $\mathrm{L} 6$ and antidromic latency of visually responsive and visually unresponsive $C G$ neurons. $B$, Strong relationship between antidromic latency and maximal responding to optimal visual stimulation of $C G$ neurons within the superficial $400 \mu \mathrm{m}$ of $L 6$ (B bracket in $A$, from -800 to $-1200 \mu \mathrm{m}$ in depth). C, Conversely, long-latency $(G$ neurons ( $C$ bracket in $A, 22+\mathrm{ms}$ ) have very low $\mathrm{F} 1$ response rates regardless of their depth in $\mathrm{L} 6$.

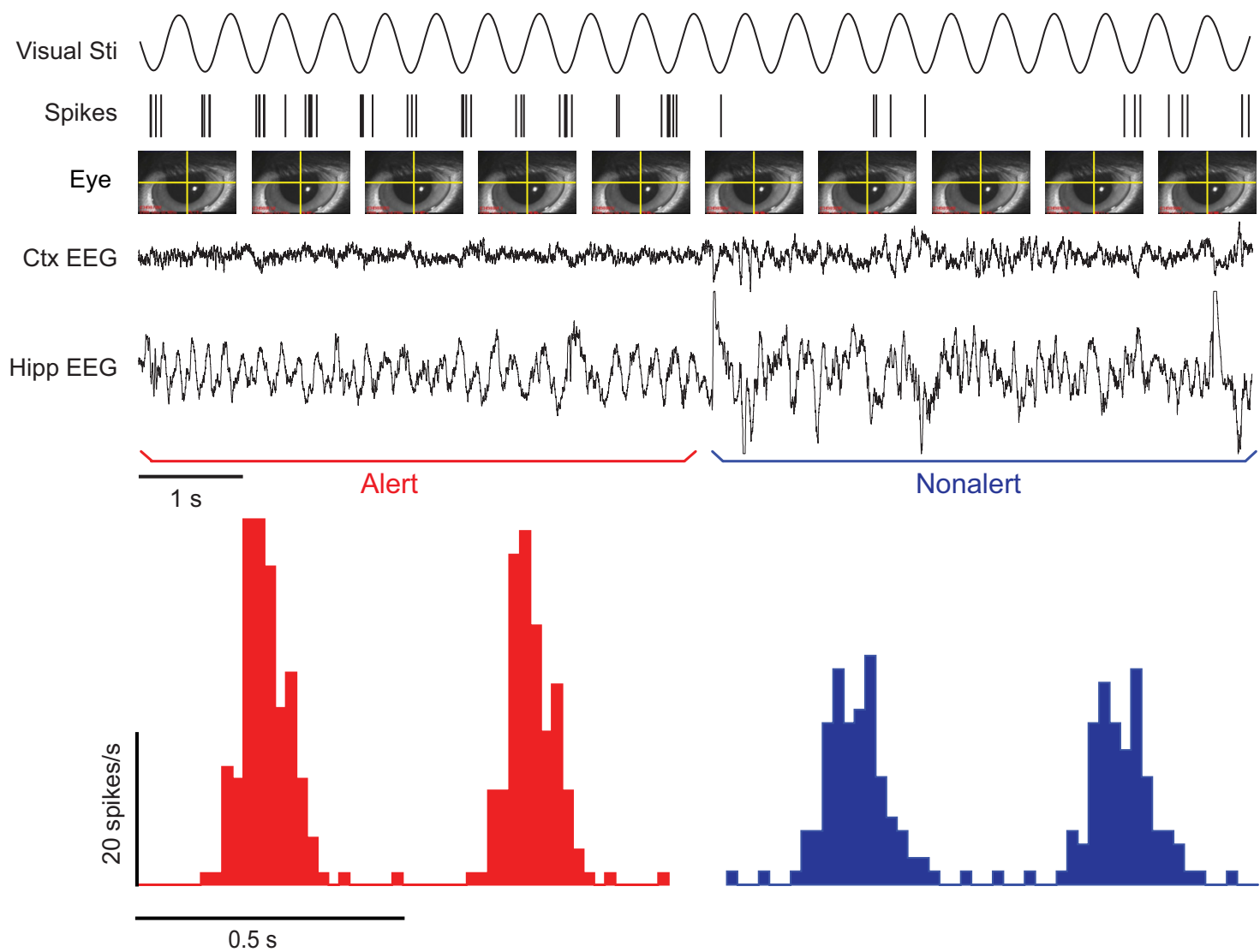

Figure 12. Responses to optimal drifting gratings of an $\mathrm{L} 6 \mathrm{CG}$ neuron during alert/nonalert transitions. One transition from the alert state to the nonalert state and PSTHs around transition points [from $\sim 5 \mathrm{~s}$ alert (red) to $\sim 5 \mathrm{~s}$ nonalert (blue)] are shown. Top to bottom, Visual stimulus (time in $x$-axis and luminance in $y$-axis), cell spike rasters, snap shots extracted from the video recording of the eye (1 per second), and hippocampal (Hipp) and cortical (Ctx) EEG are shown.

All visually responsive CG neurons had "simple" RFs, generated sustained responses, and F1/F0 ratios of $>1$. However, within this seemingly homogeneous population, axonal conduction times were very diverse and were strongly related to multiple visual response properties. Most notable was the strong relationship between conduction times and maximal response rates to drifting grating stimulation (F0 and $\mathrm{F} 1$ values), with slowly conducting
CG neurons showing the lowest rates. Related, but distinct, from these values were the minimal visually driven interspike intervals, also strongly related to axonal conduction time (Fig. $5 A-D$ ), and the minimal interspike intervals generated by 2 -pulse electrical stimulation of the axon (Fig. $5 E, F$ ). These latter measures reflect an "entrainment interval" (Kocsis et al., 1979) that follows the relative refractory period and precedes the supernormal period 
A1

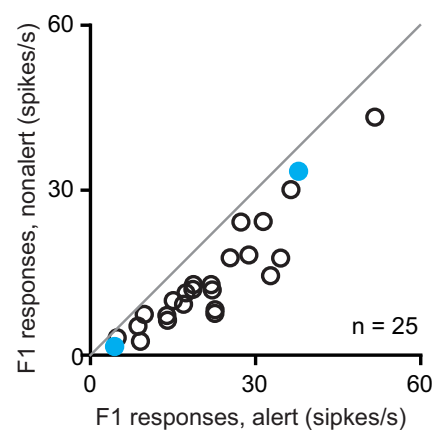

B1

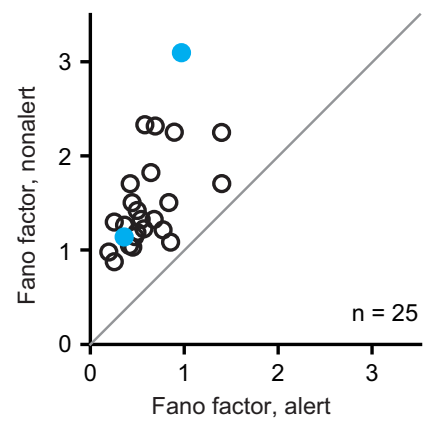

C1

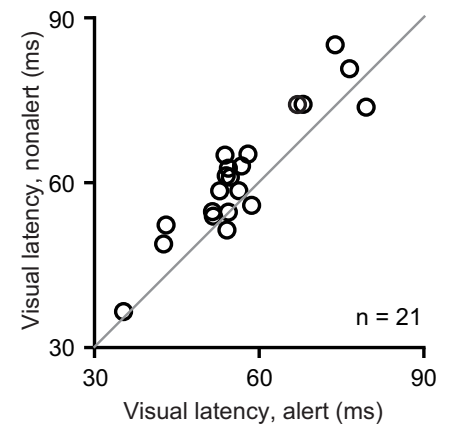

A2

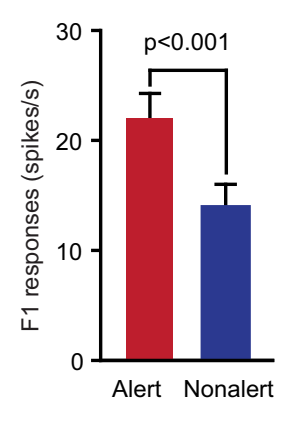

B2

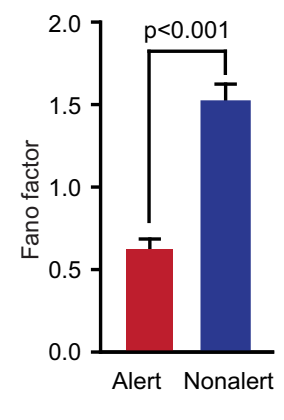

C2

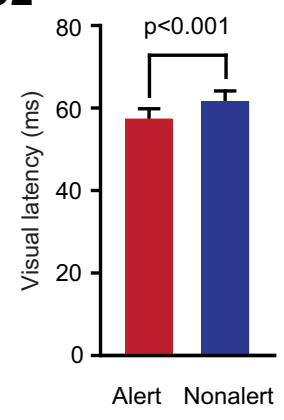

A3

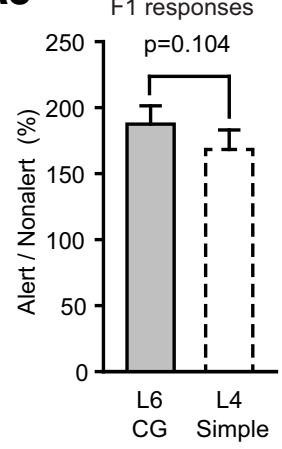

B3

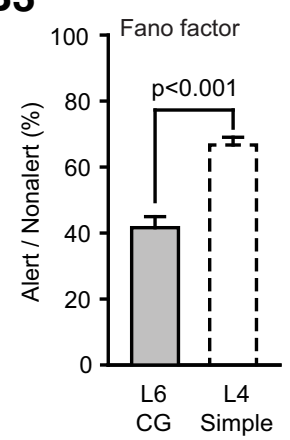

stationary stimuli, the fast-conducting CG neurons are better suited to detect fastmoving, low-intensity transients.

L6 receives far fewer geniculocortical synapses than L4, and most thalamic input is concentrated in superficial L6 (Humphrey et al., 1985). This could explain why fast-conducting CG neurons with strong visual responses were only found in superficial L6. However, slowly conducting CG neurons were also found superficially, and they responded weakly to visual stimulation (Fig. 11B), indicating that response strength is more tightly linked to axonal conduction time than to depth within L6. The similar response strength of slowly conducting deep versus superficial CG neurons (Fig. 11C) further supports this view.

\section{Other species and cortical regions}

There is general agreement that L6 corticothalamic neurons display a broad range of conduction times (e.g., Ferster and Lindstrom, 1983; Sirota et al., 2005, Swadlow and Weyand, 1987; Briggs and Usrey, 2009), but the relation between axonal conduction times and sensory response properties is poorly understood. Thus, several studies found that cat L6 CG populations have both fast-conducting "complex cells" and more slowly conducting "simple" cells (e.g., Gilbert, 1977; Harvey, 1980; Tsumoto and Suda, 1980; Grieve and Sillito, 1995). However, the presence of fast-conducting complex cells in superficial L6 was questioned by Ferster and Lindstrom (1983) who concluded that the putative fast-conducting CG complex cells were likely to be "cortico-collicular cells of L5." CG neurons have not been characterized in awake cats, but the need for such studies was highlighted by findings of Tsumoto and Suda (1980), who reported silent, visually unresponsive, slowly conducting CG neurons in deep L6. However, barbiturate anesthesia in these experiments may have suppressed spontaneous and sensory-evoked re-

Figure 13. Alertness increases $F 1$ responses, response reliability, and decreases visual response latency of $L 6 C G$ neurons. A1, Scattergram of F1 responses for each cell in the two states. $\boldsymbol{A 2}$, Population statistics of state effect on F1 responses. $\boldsymbol{A}$, Left, The same data presented in $\boldsymbol{A 1}$, plotted as the mean $\mathrm{F} 1$ response in the alert state, relative to the $\mathrm{F} 1$ when nonalert. $\boldsymbol{A} \boldsymbol{3}$, Right, The same measure, but for $L 4$ simple cells ( $L 4$ data derived from data in Zhuang et al., 2014). B1, Scattergram of Fano factor values for each cell in the two states. $\boldsymbol{B 2}$, Population statistics for state effects on Fano factor values. $\boldsymbol{B} 3$, Left, The same data presented in $\boldsymbol{B}$, plotted as the mean Fano factor in the alert state, relative to the Fano factor when nonalert. $\mathbf{B}$, Right, The same measure, but for L4 simple cells (L4 data from Zhuang et al., 2014). C1, Scattergram of visual latencies for each cell in the two states. C2, Population statistics of state effect on visual latency.

seen in corticothalamic and many other central axons (GardnerMedwin, 1972; Swadlow and Waxman, 1975; Swadlow, 1989, 1990; Beierlein et al., 2002; Kwegyir-Afful and Simons, 2009). Thus, visually driven firing rates, generated by presynaptic and postsynaptic mechanism of the soma/dendritic tree are, somehow, well correlated with the highest attainable axonal firing rates.

In cats, LGN neurons with fast-conducting axons receive faster retinal input (Cleland et al., 1971; Wilson et al., 1976). Similarly, fast-conducting CG neurons had shorter visual response latencies than slower CG neurons. CG neurons with faster conducting axons also showed more directional selectivity, higher peak temporal frequencies, and more contrast sensitivity (lower C-50 values). Thus, whereas all CG neurons respond continuously to sponses. Work by Briggs and Usrey (2009) on antidromically identified CG neurons in awake monkeys is methodologically similar to the present work. They found that CG cells display a broad spectrum of axonal conduction times and include complex (fast, and slowly conducting groups) and simple cells (an intermediate group). Importantly, they found these groups to have response properties consistent with parvocellular, magnocellular, and koniocellular LGN layers, supporting notions of parallel visual streams in the primate CG system (Fitzpatrick et al., 1994; Briggs et al., 2016). Here, by contrast, all visually responsive CG neurons were of the same RF class (simple, with sustained responses) and had numerous properties that varied in a continuous manner with axonal conduction time. Moreover, we failed to find any significant bimodality in any of the visual or other mea- 
A

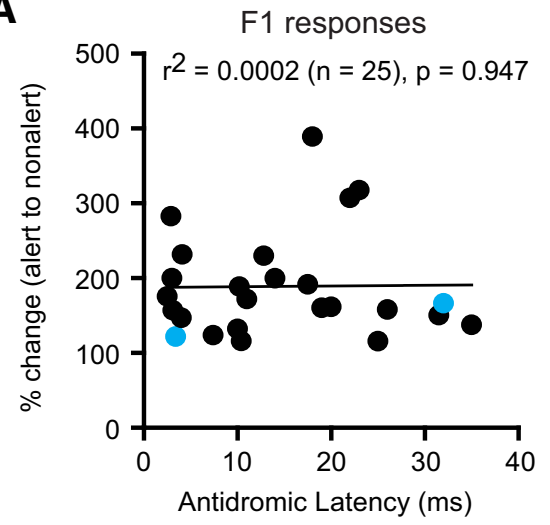

D

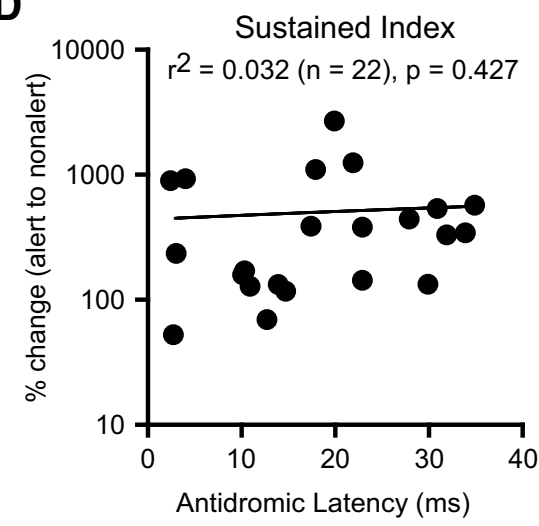

B

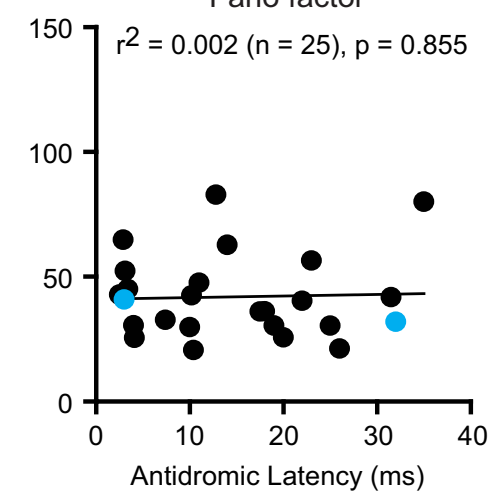

E

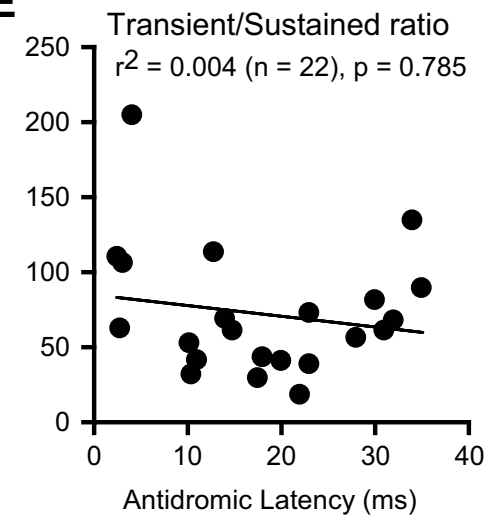

C

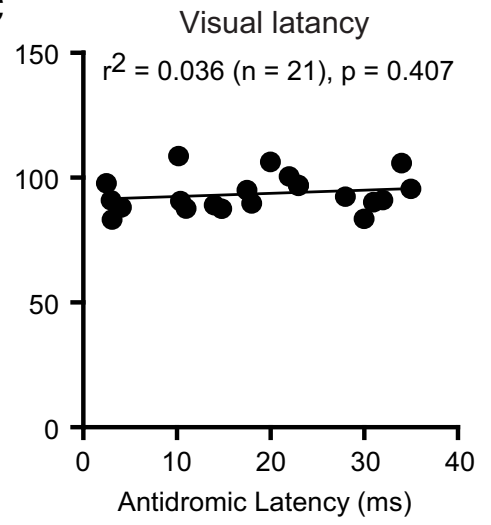

Figure 14. Lack of interaction between effects of brain state and effects of axonal conduction time on CG visual response properties. Regardless of the CG antidromic latency, F1 responses ( $\boldsymbol{A})$ were greater when alert, Fano factor $(\boldsymbol{B})$ and visual latency $(\boldsymbol{C})$ were reduced when alert, sustained responding (the Sustained Index) $(\boldsymbol{D})$ was increased when alert, and the Transient/Sustained ratio $(\boldsymbol{E})$ was reduced when alert.

sures that we studied. Our results therefore seem most consistent with a single CG visual stream in the rabbit, which varies in sensory responsiveness along the continuum of axonal conduction times.

L6 somatosensory corticothalamic neurons of rabbit (Swadlow, 1989, 1990, 1991) and rat (Kelly et al., 2001; Kwegyir-Afful and Simons, 2009) also display a wide range of axonal conduction times and very low spontaneous firing rates. Moreover, in each of these cortical areas, the slowest axons tended to lack sensory responsiveness. Similarly, in motor cortex of awake cats (Sirota et al., 2005), L6 corticothalamic neurons display axonal conduction times of up to $50 \mathrm{~ms}$, show exceedingly low spontaneous firing rates (often $<1$ spike/min), and the slowest conducting neurons are largely unresponsive during locomotion.

Thus, there is remarkable agreement across sensory and motor cortical regions and diverse mammalian orders, that many L6 corticothalamic axons conduct impulses at exceedingly low velocities, and that many of the slowest are silent and unresponsive, even when subjects are aroused and behaving. Monkey CG neurons seem to provide an exception to this, however, in having high rates of spontaneous activity ( $\sim 20$ spikes/s) (Briggs and Usrey, 2009). In the present work, EEG arousal did not make otherwise unresponsive CG neurons responsive and immediate neighbors of unresponsive neurons were often highly responsive. Moreover, in motor cortex of rabbits and cats, unresponsive cells remain silent even during locomotion (Beloozerova et al., 2003; Sirota et al., 2005). Such resounding silence is enigmatic. However, in somatosensory cortex of rabbits (Swadlow and Hicks, 1996) and rats (Kwegyir-Afful and Simons, 2009), many silent, slowly conducting L6 projection neurons have subthreshold RFs. We therefore suggest that subthreshold receptive may also be present in some of the otherwise silent CG neurons studied here, and that a continuum of visual responsiveness (from strongly suprathreshold, to weakly suprathreshold, to subthreshold) may span the entire spectrum of CG axonal conduction times.

The function of such silent and unresponsive neurons and their very slowly conducting axons is a puzzle. Possibly, they reflect a plastic reduction of sensory responsiveness in CG neurons which, over a lifetime, failed to attract sufficient excitatory synaptic input, with resulting axonal consequences (i.e., the lack of synaptic activity leading to progressive reduction in axon diameter and consequent slowing of impulse conduction). Such progressive and significant slowing of impulse conduction, at rates of $1 \%-2 \% / d$, has been documented in single cortical axons over periods of many months (Swadlow, 1982, 1985). Rather than dying, such neurons may go "off-line" and constitute a "plastic reserve" which could, for a variety of reasons (e.g., death of neighboring neurons, increase in relevant sensory stimulation), be reintegrated into the local circuit.

\section{Alert versus nonalert brain states}

Alert/nonalert transitions profoundly influenced visually responsive CG neurons. We focused on two response properties shown to be strongly influenced by alertness in L4 (Zhuang et al., 2014): (1) the response strength to an optimal drifting grating (F1, F0) and (2) response reliability (Fano factor). F1 responses were increased by a mean of $87 \%$ during alertness, somewhat more than what we saw in L4 simple cells (Fig. 13A3). This dif- 
ference was not statistically significant, however. Response reliability was enhanced to an even greater degree during alertness (lower Fano factors), also more so than was seen in L4 simple cells (Fig. 13B3), and this difference was highly significant. Moreover, although visual response latencies of L4 neurons were not affected by alertness, L6 CG latencies were significantly shortened. However, no visually unresponsive neurons became responsive during arousal, and brain state did not affect the response linearity (F1/F0 ratios) and had little effect on the profoundly low rates of CG spontaneous firing.

It has been estimated that only $30 \%-46 \%$ of response strength in L4 neurons is due to direct LGN input, whereas the remainder is due to intracortical amplification (Ferster et al., 1996; Chung and Ferster, 1998; Lien and Scanziani, 2013). We suggest that the visual responses of L6 CG neurons are even less dependent on LGN inputs than the visual responses of L4 simple cells. Although CG neurons may receive LGN input, the number of geniculocortical synapses in L6 is far less than in L4 (Humphrey et al., 1985). It is therefore likely that most CG neurons receive fewer "driving" LGN synapses (Sherman and Guillery, 1998) than L4 simple cells, and that CG visual responses are, to a greater extent, due to intracortical mechanisms. If so, this could explain why L6 CG neurons have longer response latencies to optimal flashing stimuli than $\mathrm{L} 4$ simple cells (Fig. 6D). Also, because a higher proportion of cascading intracortical synapses would add more opportunities for state-dependent modulation of CG neurons, this could also account for the stronger effects of arousal on response reliability of CG neurons compared with L4 simple cells, and the greater effect of brain state on CG response latency. Finally, despite the multiple differences in response properties between CG neurons with fast versus slowly conducting axons, they are equally affected by rapid shifts in awake brain states.

\section{References}

Albrecht DG, Hamilton DB (1982) Striate cortex of monkey and cat: contrast response function. J Neurophysiol 48:217-237. Medline

Alitto HJ, Usrey WM (2003) Corticothalamic feedback and sensory processing. Curr Opin Neurobiol 13:440-445. CrossRef Medline

Alonso JM, Usrey WM, Reid RC (2001) Rules of connectivity between geniculate cells and simple cells in cat primary visual cortex. J Neurosci 21:4002-4015. Medline

Beierlein M, Connors BW (2002) Short-term dynamics of thalamocortical and intracortical synapses onto layer 6 neurons in neocortex. J Neurophysiol 88:1924-1932. Medline

Beloozerova IN, Sirota MG, Swadlow HA (2003) Activity of different classes of neurons of the motor cortex during locomotion. J Neurosci 23:10871097. Medline

Bereshpolova Y, Amitai Y, Gusev AG, Stoelzel CR, Swadlow HA (2007) Dendritic backpropagation and the state of the awake neocortex. J Neurosci 27:9392-9399. CrossRef Medline

Bereshpolova Y, Stoelzel CR, Zhuang J, Amitai Y, Alonso JM, Swadlow HA (2011) Getting drowsy? Alert/nonalert transitions and visual thalamocortical network dynamics. J Neurosci 31:17480-17487. CrossRef Medline

Bezdudnaya T, Cano M, Bereshpolova Y, Stoelzel CR, Alonso JM, Swadlow HA (2006) Thalamic burst mode and inattention in the awake LGNd. Neuron 49:421-432. CrossRef Medline

Briggs F, Usrey WM (2005) Temporal properties of feedforward and feedback pathways between the thalamus and visual cortex in the ferret. Thalamus Relat Syst 3:133-139. CrossRef Medline

Briggs F, Usrey WM (2009) Parallel processing in the corticogeniculate pathway of the macaque monkey. Neuron 62:135-146. CrossRef Medline

Briggs F, Kiley CW, Callaway EM, Usrey WM (2016) Morphological substrates for parallel steams of corticogeniculate feedback originating in both V1 and V2 of the Macaque monkey. Neuron 90:388-399. CrossRef Medline

Cano M, Bezdudnaya T, Swadlow HA, Alonso JM (2006) Brain state and contrast sensitivity in the awake visual thalamus. Nat Neurosci 9:12401242. CrossRef Medline
Chung S, Ferster D (1998) Strength and orientation tuning of the thalamic input to simple cells revealed by electrical evoked cortical suppression. Neuron 20:1177-1189. CrossRef Medline

Cleland BG, Dubin MW, Levick WR (1971) Sustained and transient neurones in the cat's retina and lateral geniculate nucleus. J Physiol 217:473496. CrossRef Medline

Dellal SS, Luo R, Otis TS (2012) GABAA receptors increase excitability and conduction velocity of cerebellar parallel fiber axons. J Neurophysiol 107: 2958-2970. CrossRef Medline

Ferster D, Chung S. Wheat H (1996) Orientation selectivity of thalamic input to simple cells of cat visual cortex. Nature 380:249-252. CrossRef Medline

Ferster D, Lindström S (1983) An intracellular analysis of geniculo-cortical connectivity in area 17 of the cat. J Physiol 342:181-215. CrossRef Medline

Fitzpatrick D, Usrey WM, Schofield BR, Einstein G (1994) The sublaminar organization of corticogeniculate neurons in layer 6 of macaque striate cortex. Vis Neurosci 11:307-315. CrossRef Medline

Gardner-Medwin AR (1972) An extreme supernormal period in cerebellar parallel fibers. J Physiol 222:357-371. CrossRef Medline

Gilbert CD (1977) Laminar differences in receptive field properties of cells in cat primary visual cortex. J Physiol 268:391-421. CrossRef Medline

Grieve KL, Sillito AM (1995) Differential properties of cells in the feline primary visual cortex providing the corticofugal feedback to the lateral geniculate nucleus and visual claustrum. J Neurosci 15:4868-4874. Medline

Harris KD, Thiele A (2011) Cortical state and attention. Nat Rev Neurosci 12:509-523. CrossRef Medline

Harvey AR (1980) A physiological analysis of subcortical and commissural projections of area 17 and 18 of the cat. J Physiol 302:507-534. CrossRef Medline

Humphrey AL, Sur M, Uhlrich DJ, Sherman SM (1985) Projection patterns of individual X- and Y-cell axons from the lateral geniculate nucleus to cortical area 17 in the cat. J Comp Neurol 233:159-189. CrossRef Medline

Jones JP, Palmer LA (1987) The two-dimensional spatial structure of simple receptive fields in cat striate cortex. J Neurophysiol 58:1187-1211. Medline

Kelly MK, Carvell GE, Hartings JA, Simons DJ (2001) Axonal conduction properties of antidromically identified neurons in rat barrel cortex. Somatosens Mot Res 18:202-210. CrossRef Medline

Kocsis JD, Swadlow HA, Waxman SG, Brill MH (1979) Variation in conduction velocity during the relative refractory and supernormal periods: a mechanism for impulse entrainment in central axons. Exp Neurol 65: 230-236. CrossRef Medline

Kwegyir-Afful EE, Simons DJ (2009) Subthreshold receptive field properties distinguish different classes of corticothalamic neurons in the somatosensory system. J Neurosci 29:964-972. CrossRef Medline

Lee SH, Dan Y (2012) Neuromodulation of brain states. Neuron 76:209_ 222. CrossRef Medline

Lien AD, Scanziani M (2013) Tuned thalamic excitation is amplified by visual cortical circuits. Nat Neurosci 16:1315-1323. CrossRef Medline

McGinley MJ, Vinck M, Reimer J, Batista-Brito R, Zagha E, Cadwell CR, Tolias AS, Cardin JA, McCormick DA (2015) Waking state: rapid variations modulate neural and behavioral responses. Neuron 87:1143-1161. CrossRef Medline

Meeks JP, Mennerick S (2007) Action potential initiation and propagation in CA3 pyramidal axons. J Neurophysiol 97:3460-3472. CrossRef Medline

Merrill EG, Wall PD, Yaksh TL (1978) Properties of two unmyelinated fibre tracts of the central nervous system: lateral Lissauer tract, and parallel fibres of the cerebellum. J Physiol (Lond) 284:127-145. CrossRef Medline

Naka KI, Rushton WA (1966) S-potentials from luminosity units in the retina of fish (Cyprinidae) J Physiol 185:587-599. CrossRef

Nowak LG, Sanchez-Vives MV, McCormick DA (2008) Lack of orientation and direction selectivity in a subgroup of fast-spiking inhibitory interneurons: cellular and synaptic mechanisms and comparison with other electrophysiological cell types. Cereb Cortex 18:1058-1078. CrossRef

Peirce JW (2007) The potential importance of saturating and supersaturating contrast response functions in visual cortex. J Vis 7:13. CrossRef Medline

Ringach DL, Shapley RM, Hawken MJ (2002) Orientation selectivity in macaque V1: diversity and laminar dependence. J Neurosci 22:5639-5651. Medline

Sherman SM, Guillery RW (1998) On the actions that one nerve cell can 
have on another: distinguishing "drivers" from "modulators." Proc Natl Acad Sci U S A 95:7121-7126.

Sirota MG, Swadlow HA, Beloozerova IN (2005) Three channels of corticothalamic communication during locomotion. J Neurosci 25:5915-5925. CrossRef Medline

Skottun BC, De Valois RL, Grosof DH, Movshon JA, Albrecht DG, Bonds AB (1991) Classifying simple and complex cells on the basis of response modulation. Vision Res 31:1079-1086. CrossRef Medline

Stoelzel CR, Bereshpolova Y, Gusev AG, Swadlow HA (2008) The impact of an LGNd impulse on the awake visual cortex: synaptic dynamics and the sustained/transient distinction. J Neurosci 28:5018-5028. CrossRef Medline

Stoelzel CR, Bereshpolova Y, Swadlow HA (2009) Stability of thalamocortical synaptic transmission across awake brain states. J Neurosci 29:68516859. CrossRef Medline

Swadlow HA (1982) Impulse conduction in the mammalian brain: physiological properties of individual axons studied for several months. Science 218:911-913. CrossRef Medline

Swadlow HA (1985) Physiological properties of individual cerebral axons studied in vivo for as long as one year. J Neurophysiol 54:1346-1362. Medline

Swadlow HA (1989) Efferent neurons and suspected interneurons in S-1 vibrissa cortex of the awake rabbit: receptive fields and axonal properties. J Neurophysiol 62:288-308. Medline

Swadlow HA (1990) Efferent neurons and suspected interneurons in S-1 forelimb representation of the awake rabbit: receptive fields and axonal properties. J Neurophysiol 63:1477-1498. Medline

Swadlow HA (1991) Efferent neurons and suspected interneurons in second somatosensory cortex of the awake rabbit: receptive fields and axonal properties. J Neurophysiol 66:1392-1409. Medline

Swadlow HA (1998) Neocortical efferent neurons with very slowly conducting axons: strategies for reliable antidromic identification. J Neurosci Methods 79:131-141. CrossRef Medline

Swadlow HA, Hicks TP (1996) Somatosensory cortical efferent neurons of the awake rabbit: latencies to activation via supra- and subthreshold receptive fields. J Neurophysiol 75:1753-1759. Medline

Swadlow HA, Waxman SG (1975) Observations on impulse conduction along central axons. Proc Natl Acad Sci U S A 72:5156-5159. CrossRef Medline

Swadlow HA, Waxman SG (1976) Variations in conduction velocity and excitability following single and multiple impulses of visual callosal axons in the rabbit. Exp Neurol 53:128-150. CrossRef Medline

Swadlow HA, Waxman SG, Rosene DL (1978) Latency variability and the identification of antidromically activated neurons in mammalian brain. Exp Brain Res 32:439-443. CrossRef Medline

Swadlow HA, Weyand TG (1981) Efferent systems of the rabbit visual cortex: laminar distribution of the cells of origin, axonal conduction velocities, and identification of axonal branches. J Comp Neurol 203:799-822. CrossRef Medline

Swadlow HA, Weyand TG (1985) Receptive-field and axonal properties of neurons in the dorsal lateral geniculate nucleus of awake unparalyzed rabbits. J Neurophysiol 54:168-183. Medline

Swadlow HA, Weyand TG (1987) Corticogeniculate neurons, corticotectal neurons, and suspected interneurons in visual cortex of awake rabbits: receptive-field properties, axonal properties, and effects of EEG arousal. J Neurophysiol 57:977-1001. Medline

Swadlow HA, Gusev AG (2001) The impact of "bursting" thalamic impulses on a neocortical synapse. Nat Neurosci 4: 402-408.

Swadlow HA, Bereshpolova Y, Bezdudnaya T, Cano M, Stoelzel CR (2005) A multi-channel, implantable microdrive system for use with sharp, ultra-fine "Reitboeck" microelectrodes. J Neurophysiol 93:2959-2965. CrossRef Medline

Tsumoto T, Suda K (1980) Three groups of cortico-geniculate neurons and their distribution in binocular and monocular segments of cat striate cortex. J Comp Neurol 193:223-236. CrossRef Medline

Waxman SG, Bennett MV (1972) Relative conduction velocities of small myelinated and non-myelinated fibres in the central nervous system. Nat New Biol 238:217-219. CrossRef Medline

Waxman SG, Swadlow HA (1976) Morphology and physiology of visual callosal axons: evidence for a supernormal period in central myelinated axons. Brain Res 113:179-187. CrossRef Medline

Wilson PD, Rowe MH, Stone J (1976) Properties of relay cells in cat's lateral geniculate nucleus: a comparison of W-cells with X-and Y-cells. J Neuropshysiol 39:1193-1209. Medline

Zhuang J, Stoelzel CR, Bereshpolova Y, Huff JM, Hei X, Alonso JM, Swadlow HA (2013) Layer 4 in primary visual cortex of the awake rabbit: contrasting properties of simple cells and putative feedforward inhibitory interneurons. J Neurosci 33:11372-11389. CrossRef Medline

Zhuang J, Bereshpolova Y, Stoelzel CR, Huff JM, Hei X, Alonso JM, Swadlow HA (2014) Brain state effects on L4 of the awake visual cortex. J Neurosci 34:3888-3900. CrossRef Medline 